\title{
Adverse acculturation conditions and wellbeing in the workplace: The mediating role of separation
}

\author{
Dudley Gustav de Koker \\ 21799210
}

Mini-dissertation submitted in partial fulfilment of the requirements Of the degree Masters in Business Administration at the

Potchefstroom Business School, Potchefstroom Campus of the North-West University

Study Leader: Prof. L. T. B. Jackson

November 2011

Potchefstroom 


\section{ACKNOWLEDGEMENTS}

The past three years were hard work, bringing challenges, disappointments but also success. I have learned things which benefited me in various ways and would like to thank the following people for their support and encouragement through my MBA journey:

- First and foremost, my gratitude goes out to our lord and saviour, unto him goes all the glory;

- Secondly, my gratitude goes to my supervisor Prof. Leon Jackson who supported and guide me through this project; and

- Last but not least, my family, for their patience and support. 


\section{REMARKS}

The reader is reminded of the following:

- The references as well as the editorial style as prescribed by the Publication Manual (4 $4^{\text {th }}$ edition) of the American Psychological Association (APA) were followed in this thesis. This practice is in line with the policy of the Programme in Industrial Psychology of the NWU to use APA style in all scientific documents as from January 1999.

- The mini-dissertation is submitted in the form of a research articles. 
Table of Contents

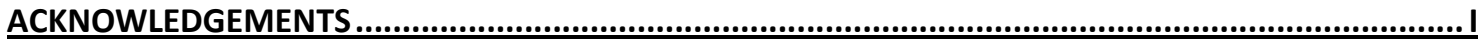

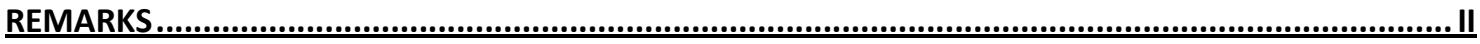

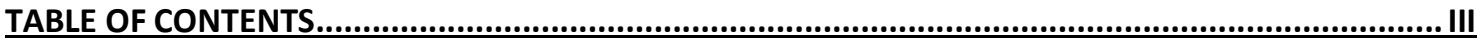

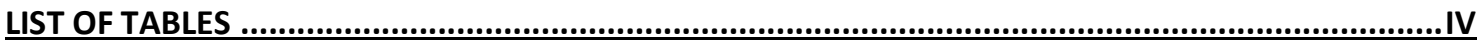

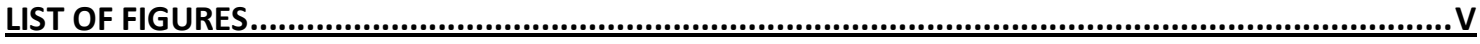

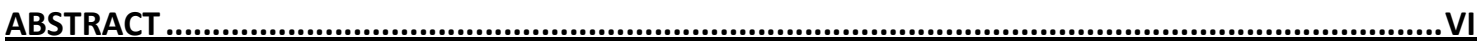

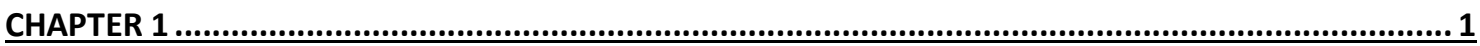

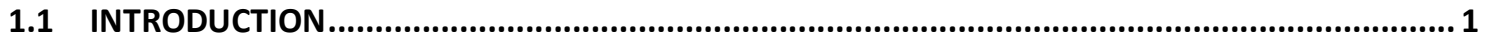

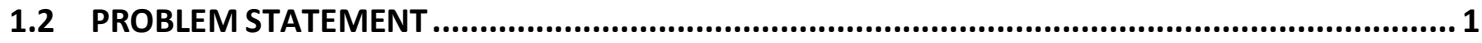

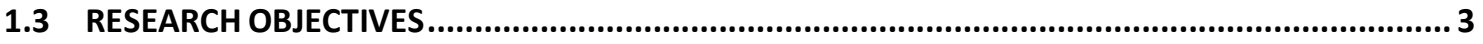

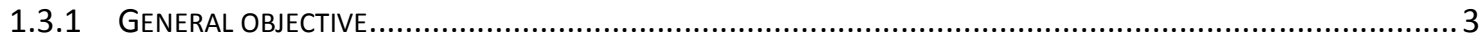

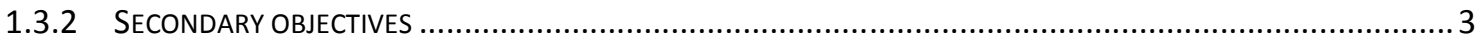

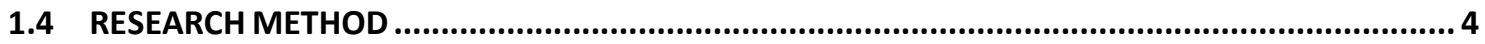

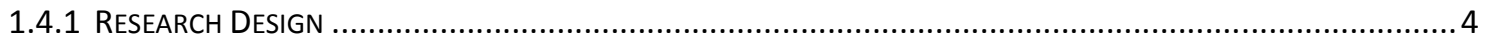

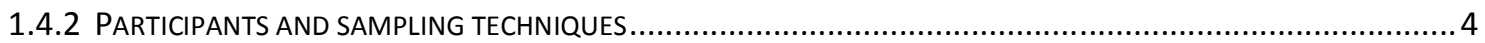

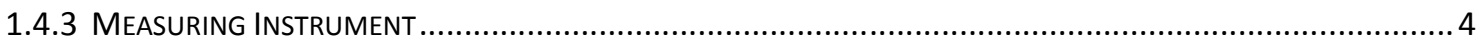

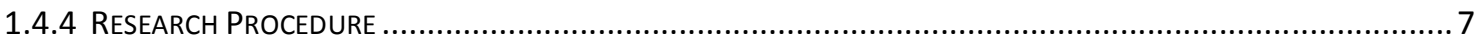

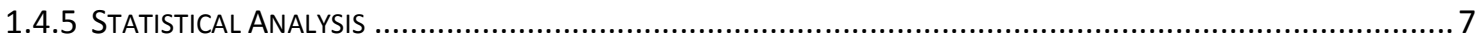

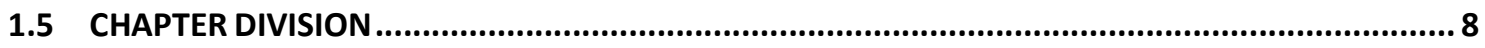

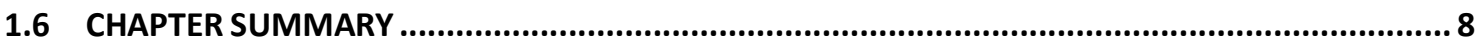

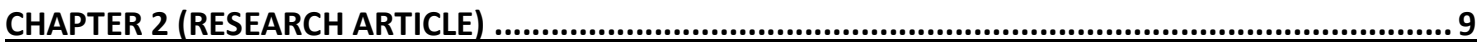

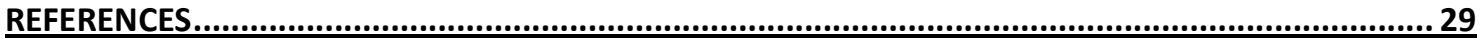

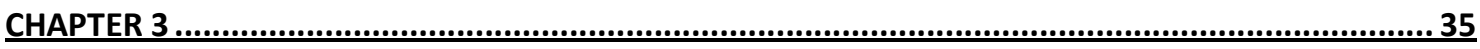

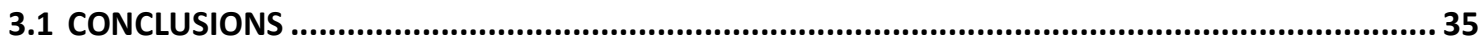

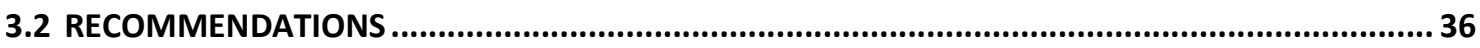

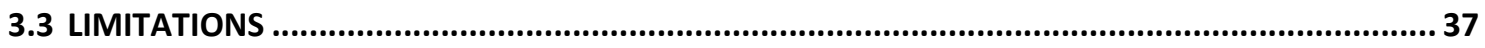

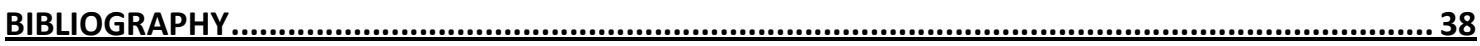

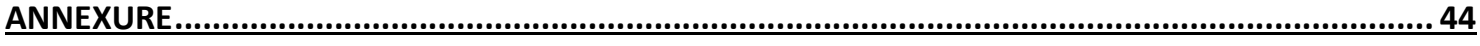

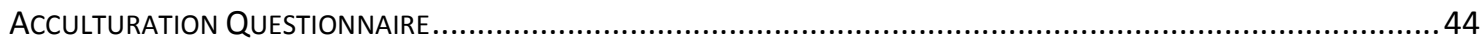




\section{LIST OF TABLES}

Table

Description

Page

\section{Research Article}

Table $1 \quad$ Participant Characteristics

19

Table 2 Descriptive statistics $(n=288)$

23

Table 3 Correlations: acculturation constructs and outcomes

24

Table 4 Mediation effects of separation in the workplace

26 


\section{LIST OF FIGURES}

Table

Description

Page

\section{Research Article}

Figure 1 Results of the Mediating Acculturation Model Analysis 


\section{ABSTRACT}

Objectives: To assess the mediating role of ethnic separation in the relationship between adverse acculturation conditions and wellbeing in the workplace. The analysis entails establishment of how acculturation conditions, such as segregation demands, racism and discrimination, affect employees' intentions to quit and their physical and psychological health. In addition, it aims to determine the mediating role of ethnic separation between adverse conditions and wellbeing.

Design: The convenient sample covers most sectors, such as the retail sector, banking sector, mining sector, police service, municipality, and individuals between 18 and 60 years living in South Africa. A total of 327 participants were eligible to complete an acculturation questionnaire during 2011.

Results: The study showed that racism, discrimination, segregation and separation, affect acculturation outcomes, with intentions to quit having a particularly adverse effect. Racism and discrimination affect people's physical and psychological health. Furthermore, results showed that employees, who experience some sort of mainstream segregation, racism and discrimination, are more likely to choose to distance themselves and prefer separation.

Conclusions: The article concludes that racism, discrimination, segregation and separation affect acculturation outcomes adversely. As a result, employees' preferred acculturation strategy is to separate from those who discriminate and/or are racist. 


\section{CHAPTER 1}

\subsection{INTRODUCTION}

In Chapter 1, the problem statement, research objectives, and research methodology will be discussed, followed by a discussion of the research methods, with details regarding the research procedure, participants, measuring instruments, and statistical analysis.

In looking at the long history of racial discrimination throughout the world, most societies, especially the larger ones, have practiced some form and degree of racial discrimination. In South Africa, Australia, and the United States of America (USA), the black and indigenous populations have faced heavy suffering in the workplace and at their homes (Devine, 2008). Various news headlines (i.e. Van Wyk, 2011) highlighted allegations of racism and discrimination in the workplace, and one can discern that, despite the introduction of universal suffrage and an enlightened Constitution in 1994, racism and discrimination continue to affect South Africans in a significant way, impeding progress to reverse previous apartheid policies and form a nation of unity.

Against this background, the research behind this paper investigated adverse acculturation conditions and wellbeing in the workplace in sectors such as the retail, banking, mining, police service, and municipalities. It also endeavoured to determine the mediating role of ethnic separation in the relationship between these adverse conditions and wellbeing as measured by job satisfaction, organisational commitment and subjective experiences of work success.

\subsection{PROBLEM STATEMENT}

As South Africa emerged from isolation into the global economy and began a process of socio-economic transformation, different drivers for effective management of human resources became known (Ali, 2008). 
The Bill of Rights decreed that no discrimination would be permitted on the grounds of race, sex, gender, sexual orientation, ethnic or social origin, colour, age, disability, pregnancy, religion, conscience, belief, language, marital status, birth, or culture. Although human and civil rights laws legally require non-discriminatory treatment of minorities, many blacks continuously face racism and discrimination in the workplace, at restaurants, stores, hotels, and other public places (Feagan \& Melvyn, 2009).

On the other hand it can be argued that not all discrimination stems from racism. D'Souza (2009) argues that discrimination is often based on coherent or commonsense assumptions about a person's appearance, taking into account factors such as age, ethnicity, clothing, or people's behaviour. Research by Elizabeth and Christopher (2010) also finds that workers, as indicated by job authority, promotion experience, and union membership, are more likely to experience racial discrimination in the workplace.

In addition, gender is an issue of relevance to the research, with Pavalko, Mossakowski and Hamilton (2003) arguing that one might expect that the severity of racial discrimination would produce a stronger effect on the health of black than white women. However, research (Pavalko et al., 2003) challenges a simple connection between racial discrimination experiences and health. For black women who experienced racial discrimination throughout their lives, it is argued that those who do not overreact to racial discrimination may be effective in minimising psychological effects, thus lessening such effects arising from racial discrimination for black women. On the other hand, there is growing evidence (Pavalko et al., 2003) that such a response may have long-term consequences for physical health outcomes.

Jackson, Van de Vijver and Burckard (2011) have revealed that separation demands have various indirect adverse effects that were significant, as well as direct adverse effects that were insignificant, concluding that the association between acculturation demands and physical and psychological ill-health is fully mediated by a separation acculturation strategy. Furthermore, segregation and subtle racism showed significant indirect effects on both physical and psychological ill-health. 
Halpern, (1993); Noh, S., Beiser, M., Kaspar, V., Hou, F., \& Rummens, J. (1999) has reported that the experience of racial discrimination has a significant negative effect on a person's wellbeing. It has been argued that such prejudice is likely to be less prevalent in culturally plural societies, but it is by no means absent (Murphy, 1965; Berry and Kalin 1995). Indeed, racism has been designated as the most serious problem facing immigrants and their mental health. Based on the problem statement the following research questions arise:

- Do adverse acculturation conditions affect intentions to quit and wellbeing?

- Does ethnic separation mediate the relation between adverse conditions and wellbeing at work?

\subsection{RESEARCH OBJECTIVES}

Achievement of the following research objectives was sought.

\subsubsection{General objective}

The primary objective of this mini-dissertation is to:

- investigate adverse acculturation conditions and wellbeing in the workplace.

\subsubsection{Secondary objectives}

The two secondary objectives of this research are to:

- determine the relationship between adverse acculturation conditions, ethnic separation and wellbeing at work, as measured by intentions to quit, physical and psychological health

- determine the mediating role of ethnic separation in the relationship between racism, discrimination, segregation and employees' intentions to quit, and their physical and psychological health. 


\subsection{RESEARCH METHOD}

This research, considering the general and specific objectives, consists of a literature review and an empirical study. Results will be presented in the form of a research article.

\subsubsection{Research Design}

The aim of the research design will be to explain the approach the research will follow. Welman, Kruger, and Mitchell (2005) explain quantitative research as an array of interpretive techniques which seek to describe, decode, translate and otherwise come to terms with the meaning of naturally occurring phenomena in the social world. The specific design used was quantitative, with questionnaires utilized to gather information.

\subsubsection{Participants and sampling techniques}

Participants were selected from a convenient sample from different sectors in the workplace, a sampling technique that is useful as it allows one to research basic data and trends and to identify relationships between different phenomena. The participants were conveniently selected from operational workers and middle management, the rational being to establish basic trends and relationships that were representative of the largest group of interest. Another reason underlying this selection was the assumption that operational workers and middle management are more prone exposure to racism and discrimination than senior management.

\subsubsection{Measuring Instrument}

Some instruments with well-established psychometric properties used in other cultural contexts were adapted (Ait Ouarasse \& Van de Vijver, 2004). Adaptations involved replacing Dutch and Moroccans with South African and own ethnic group respectively. 
All acculturation scales follow a five-point Likert format ranging from strongly agree (1) to strongly disagree (5), and some item scores were reversed before the analyses so that higher scores reflected more endorsement of the underlying attitude.

The following instruments were used:

Mainstream domain instruments

- Mainstream segregation demands (Ait Ouarasse \& Van de Vijver, 2004). This is a 12-item measure of the extent to which participants think that mainstream members hold segregationist attitudes towards minority members. A sample item is "I think that most of my fellow residents would be happy to have people from other cultures than their own to be thrown out of our organisation".

- Perceived discrimination (Ait Ouarasse \& Van de Vijver, 2004). The scale is an 11-item measure of the extent to which participants think the situation in the dormitory is discriminatory and requires them to drop their cultural characteristics. Discrimination refers to pressure exerted on the minorities to apply fully to the regulations and the general atmosphere, regardless of whether these regulations encroach on minority sensitivities. The scale contains items like "I experience discrimination in our organisation".

- Subtle racism (Subtle Racism Scale of Duckitt, 1991). This is a 10-item (four of the items were filter items and were not used in the final analysis) measure of the extent to which co-workers hold subtle racist attitudes. A sample item includes "Some groups in South Africa are getting too demanding in pushing for equal rights".

Ethnic domain instrument

- Perceived co-ethnic separation demands at work (Ait Ouarasse \& Van de Vijver, 2004) is a four-item measure of the extent to which participants think their own ethnic members want them to keep away from the majority culture. 
Separation is a strategy aimed at the prevention of mainstream influence on minority ways. The scale contains items such as "My cultural group members do not want me to make contact with members from other cultural groups in our organisation".

- Individual separation acculturation strategy. This new instrument is a three-item measure of the extent to which participants prefer contact with their own ethnic group members and do not seek participation in the 'Rainbow Nation' culture. The scale contains items such as "I actually avoid contact with members from other cultures".

Psychological acculturation outcomes

- III Health: This is an adapted version of the 18 physical health symptoms of the PSI of Spector and Jex (1998), complimented with a list of 9 common psychological complaints based on a slightly modified version of the World Health Organisation Cross-National Survey of Psychological and Somatic Symptoms (1988). The scale employs a frequency format that ranges from never (1) to every day (5). The self-report measure asks respondents to indicate whether or not in the past three months they had suffered any of the mentioned symptoms. Some examples of symptoms included on the scale are headaches, backache, fatigue, eyestrain and trouble sleeping, concentrating and constant anxiety or panic attacks.

- Intentions to quit (develop for the study). This is a three-item measure of participants' intentions to quit their work. All of the items are positively phrased.

A Biographical questionnaire was also included, dealing with basic biographical questions on age, sex, and race. 


\subsubsection{Research Procedure}

Survey questionnaires were distributed to conveniently selected employees in various sectors of the workplace. Permission was acquired through formal verbal requests to line managers. In this verbal request the purpose of the research and its advantages were explained.

The participants were selected with the help of their line managers or supervisors. Participants were given two days to complete the questionnaires which were then collected personally by the researcher.

\subsubsection{Statistical Analysis}

The statistical analysis was completed with the help of the SPSS-programme (SPSS Inc., 2003). Descriptive statistics (e.g., means, standard deviations, skew and kurtosis) was used to scrutinize data. Cronbach alpha coefficients were used to determine the internal consistency, homogeneity and uni-dimensionality of the measuring instruments (Clark \& Watson, 1995). Coefficient alpha contains important information regarding the variance proportion of the items on a scale in terms of total variance explained by that particular scale. Exploratory factor analyses were carried out to determine construct validity of the measuring instruments. Pearson productmoment correlation coefficients were used to specify the relationship between the variables in terms of statistical significance; we set the value at a $95 \%$ confidence interval $(p \leq 0.05)$. Effect sizes (Steyn, 1999) were used to decide on the practical significance of the findings. Pearson product-moment correlation coefficients were used to specify relationships between the variables. A cut-off point of 0,30 (medium effect, Cohen, 1988) was set for the practical significance of correlation coefficients. To investigate the mediating role of ethnic separation in the relations between adverse mainstream conditions and wellbeing, structural equation modelling (SEM-) was performed using AMOS 18 (Arbuckle, 2010). 


\subsection{CHAPTER DIVISION}

The chapters in this mini-dissertation are presented as follows:

Chapter 1: Research proposal (introduction and problem statement)

Chapter 2: Scientific article (literature review, research and results)

Chapter 3: Conclusions, recommendations and limitations.

\subsection{CHAPTER SUMMARY}

This chapter focused on the problem statement and objectives of the study, as well as the research methodology that will be employed. Chapter 2 will be written in the form of a research article and will focus on the literature of previous research underlying racism, discrimination, segregation, separation and acculturation outcomes. The research results will also be presented in this chapter. Chapter 3 will provide a conclusion of the study and provide recommendations and limitations. 


\title{
CHAPTER 2 \\ RESEARCH ARTICLE
}

\section{ADVERSE ACCULTURATION CONDITIONS AND WELLBEING IN THE WORKPLACE. THE MEDIATING ROLE OF SEPARATION}

\author{
Dudley Gustav de Koker \\ WorkWell Research Unit for Economics and Management Sciences, Potchefstroom Business School \\ (PBS), Economics and Management Sciences Faculty, North-West University, South Africa, 2520,
}

\begin{abstract}
This article reports on the results of research which assessed adverse acculturation conditions in the workplace. Acculturation conditions such as racism, discrimination, segregation and separation were evaluated as predictors to ascertain how it affects acculturation outcomes such as intentions to quit and ill-health, both physical and psychological, of workers in the workplace. A convenient sample $(\mathrm{N}=327)$ was taken from various sectors, for example retail, banking, mining, police service, and the municipality. The study aimed to test the mediating role of separation in the relation between adverse acculturation conditions and wellbeing as measured by illhealth and intentions to quit. The results indicated that racism, discrimination, segregation and separation, ill-health and intentions to quit were positively related. The hypothesised model was confirmed in a structural equation modelling analysis. This meant that more mainstream segregation demands, discrimination, and subtle racism, coupled with a dominant ethnic separation acculturation strategy and coethnics demanding that their members keep to themselves at work (with limited or no intercultural contact), were associated with the experiences of higher physical and psychological ill-health, and frequent thoughts of intentions to quit. In addition, mainstream segregation demands, compared to subtle racism and discrimination, were much more strongly associated with ethnic preference to separate. Recommendations for future research are provided.
\end{abstract}




\section{Introduction}

Since 1994, with the eradication of the apartheid system, South African businesses and public sectors have been confronted with large scale socio-political, cultural and economic challenges. Bhorat and Kanbur (2006) have reported that businesses were compelled to convert their unfair or discriminatory structures to ones which can accommodate the broader South African 'Rainbow Nation'. This implied transforming into institutions that are represented by the larger group of interest and still meet the needs of the economy in a sustainable manner. This is where the post-1994 transition was seen as the basis for redressing the economic deficit suffered by the majority of the South African population. As a result, apartheid policies were abandoned and policies such as employment equity, affirmative action and black economic empowerment were introduced (Bhorat \& Kanbur 2006).

Contrary to the aim of policies such as employment equity, affirmative action and black economic empowerment, research (Christopher, 2001) conducted after 1994 concluded that little change has been seen regarding deprived citizen's sociopolitical and economic conditions since liberation, and that black and white South Africans remain segregated. These occurrences impact on acculturation conditions and its associated outcomes. The acculturation context variables, racism, discrimination, segregation and individual's separation strategy, are being investigated and this article will endeavour to determine the correlations between context variables and outcomes variables in the acculturation process.

\section{Acculturation}

Marisol, Antonio, Garcia and Pumares, (2007) argue that the acculturation concept started to be used by various American social anthropologists towards the end of the 19th century. One of the first definitions of acculturation as a process came from American social anthropologists (Marisol et al., 2007, pg68), as "those phenomena which result when groups of individuals having different cultures come into continuous first-hand contact with subsequent changes in the original culture patterns of either or both groups". Graves (1967) further indicated that acculturation is a term used to describe the process of bidirectional change that takes place when 
two ethno-cultural groups come into sustained contact with each other. This definition of acculturation implies that dominant and non-dominant cultural groups are influenced and transformed by their intercultural contacts and are expected to modify some aspects of their respective culture as a means of adaptation to ethnocultural diversity. Acculturation can occur when groups of individuals with different cultures come into continuous firsthand contact then try to disassociate themselves from their group of origin to join the dominant host society (Marisol et al., 2007).

\section{Mainstream acculturation context}

Bourhis (1997) indicated that attitudes of dominant groups are important for the outcome of the acculturation process. In addition to the aforementioned, Berry, Phinney, Sam, and Velder (2006) have reported that all pluralist societies consist of both dominant and mainstream as well as minority groups. Mainstream acculturation conditions such as racism, discrimination, segregation and separation have been considered in previous research (Ait Ouarasse \& Van de Vijver, 2004; Jackson, Van de Vijver \& Burckard, 2011) and it was reported (Gee, Ro, Shariff-Marco \& Chae, 2009) that racism impacts negatively on mental health and that discrimination was associated with and impacts on mental and physical health adversely. In this study the focus is to establish the role that contextual variables such as mainstream segregation demands, subtle racism, discrimination, and separation play in the workplace and how they impact on ill-health outcomes and intentions to quit.

\section{Segregation}

Zagefka and Brown, (2002) indicate that segregation is about demands exerted on ethnicities to keep to their own, while racism and discrimination refer to negative attitudes from dominant groups during intercultural contact. Barrette, Bourhis, Personnaz, and Personnaz, (2004) have reported that dominant host members do not wish minorities to contaminate their culture, and hence accept that minority groups uphold their heritage culture on condition that they keep their distance. They are also of the opinion that segregation demands involve the demands from minority groups to keep their own culture without becoming involved in the dominant one. For Berry et al., (2006), on the other hand, segregation occurs when individuals or 
groups become separated from each other, implying that these minority individuals or groups resist the culture of the dominant ones. Dahlberg, Fredriksson and Monseny (2010) report that high levels of segregation are observed in the USA and elsewhere, and that segregation can partly be explained by differences in education, income or language between minority residents and whites. Hofmeyr (2006) has reported that South Africans have little contact with people from other ethnic groups and do not wish to increase future contact with other groups in their private space. However, contact in the workplace is unavoidable. Mainstream segregation demands are related to subtle racism, discrimination, separation and ill-health (Jackson, van de Vijver \& Burckard, 2011). Considering that inter group contact is on the increase in the South African workplace, this study will assess the role of mainstream segregation demands in the workplace in health outcomes and intentions to quit.

\section{Discrimination}

Causes of discrimination could be ascribed to different reasons and intentions from different individuals or groups, ranging from isolation of individuals or groups to attitudes of individuals or groups. Ong, Fuller-Rowell and Burrow (2009) have reported that a large-scale national survey established that almost $49 \%$ of Black respondents encountered some form of discrimination in their lifetime, for example, in not being given promotion at work, hassled by police, or even being denied service. $89.7 \%$ of these respondents reported race as a reason for the discrimination. In addition, research (Fisher, Wallace, \& Fenton, 2000) with adolescents found that $36 \%$ of African American adolescents reported having been called a racially insulting name, $46 \%$ believed that racial discrimination resulted in them receiving a lower grade than they deserved, and a further $75 \%$ reported having been bothered by store personnel because of their race. $70 \%$ reported racial experiences of others perceiving them as a threat, for example being treated suspiciously, being perceived as incompetent or being talked down to. Roscigno (2007) reported that allegations of racial discrimination in employment are more likely to arise in the high wage service and public sectors, and it is perceived that racial discrimination complaints are most likely to be of alleged discriminatory termination or firing, while complaints of discrimination in hiring or promotion are fewer. 
Pavalko et al. (2003) reported that a growing body of research points to an association between discrimination and physical and mental health outcomes. They further reported that research (Feagin 1991; Feagin \& Vera 1995) documenting discriminatory experiences leaves little doubt that these events are frustrating and stressful and do impact on physical and emotional health. Most research (Broman \& Clifford 1996) investigating the association between discrimination and health has found a significant relation between discrimination and psychological wellbeing. Given that different health problems develop and unfold in distinct and different ways, it seems unlikely that racial discrimination would have the same degree of impact across various health outcomes. Ayalon and Gum (2011) documented that overall research Kessler, Mickelson, and Williams, (1999) has shown that everyday discrimination, for example, minor but daily hassles, take a greater toll on one's health than major lifetime discrimination, i.e., major life events. Research by Moomal H. Jackson, P.B., Stein, D.J., Herman, A., Myer, L., Seedat, S., Madela-Mntla, E., Williams D.R., (2009) on discrimination and health reported that the broad perception of unfair treatment tends to adversely affect people's health, regardless of whether the discriminatory behaviour is attributed to race or other factors.

\section{Racism}

Vernellia (2008) defines racism as any action or attitude, conscious or unconscious, that undermines an individual or group based on their skin colour or race. Friedman (2000) reported that there is no issue other than racism that needs to be urgently addressed. Racism continues to dominate society and will do so for decades if assumptions held by whites regarding black incompetence are not outgrown. In addition, the defensiveness in reaction from black people allows political interference in what people think, say and do in the economy.

The last 30 years have witnessed a change in the way racial attitudes are measured (Durrheim, Baillie, and Johnstone, 2006). Early measures of racism have been characterised as old-fashioned or blatant, containing crude expressions of hate and stereotypes of racial inferiority. Heaven and Moerdyk's (1977) adaptation of Ray's anti-black scale, for example, included such items as "Blacks are not very hygiene- 
conscious" and "Blacks are a rather ugly race". On the other hand, (Swim, Aikin, Hall, \& Hunter, 1995) reported that the nature of racism has transformed from oldfashioned and blatant types to modern and subtle types. Deitch Barsky, Butz, Chan, Brief, and Bradley (2003) have reported that everyday discrimination may become more general, as blatant racism becomes less established among dominant group members. Hodson, Dovidio, and Gaertner (2002) point to empirical evidence of the adverse effects of subtle racism in the daily life of people as well as in the workplace. Recommendations for admission to colleges were investigated and a key mechanism underlying subtle racism was identified to be the credibility that people give to different types of information when they make their decisions. It was found that more racially biased white people sees the weaker aspect of a black applicant's credentials as more important for admission decisions than when the candidate was white. Dovidio and Gaertner (2000) reported that white employers were less likely to recommend black candidates for positions in the workplace or admission to colleges than the white candidates, when the formers' qualifications for the position or admission were less obvious, or even that the appropriate decision to allow blacks to succeed was more ambiguous.

\section{Ethnic acculturation context}

Heim, Hunters, and Jones (2010) reported that racial and ethnic identity is measured on how it develops over time through comparing identities on a social level, and that it is an element of how one sees oneself. Phinney (1990) argued that the way one perceives oneself is derived from belonging to, identifying with, and/or participating in the social and cultural practices of a dominant ethnic group. This normally helps to uphold one's self-esteem when faced with racism (Phinney, 1995).

Mallinckrodt and Leong (1992) reported that ethnic social support is crucial for positive wellbeing and is providing people with coping tools when they experience stressful life changes, including the stress when adjusting to unfamiliar customs, whilst Heim et al. (2010) reported that discrimination appears to draw attention or put emphasis on ethnic identification, which turns out to benefit wellbeing of minority groups. For Berry et al. (2006), separation from cultures or even confusion about where one fits in make adaptation very difficult. 
This study aimed at establishing the mediating effect of ethnic separation in the relationship between adverse mainstream conditions and ill-health, as well as intentions to quit.

\section{Ethnic separation demands}

Various ethnic groups have different attitudes towards cultural adherence and toward having contact with the dominant groups. Ward, Bochner and Furnham (2001) reported that minority groups will adopt an integration strategy, attempting to be similar to the members of the dominant group, rather than a separation strategy. Separation is an acculturation strategy that refers to the minority groups who accept their own cultural principles and uniqueness and reject the dominant culture's principles (Berry, 2001). Vedder, Van de Vijver and Liebkind, (2006) reported a significant positive correlation between ethnic separation attitudes and psychological wellbeing. Belonging to the ethnic profile was associated with poorer socio-cultural adaptation, while belonging to the national profile was associated with moderately poorer psychological and socio-cultural adaptation (Berry, 2001).

\section{Individual separation acculturation strategy}

Separation research on adolescents (Berry et al., 2006) concluded that separation is an acculturation strategy aimed at preventing the influence dominant groups have on minority groups. Research (Pham \& Harris, 2001; Zagefka \& Brown, 2002) suggests that minority groups of adolescents are mostly rooted within their own culture and show little involvement with the dominant groups. Overpowering support seems to exist for the notion that integration strategies are usually the most successful, and separation strategies are intermediate (Berry \& Kim, 1988; Berry \& Sam, 1997). However, Ward (2001) has argued that minority groups may easily move to a separation strategy should the dominant groups react negatively to their integration strategy. 


\section{Acculturation outcomes}

Ward, Bochner, \& Furnham, (2001) reported that researchers that have used variables to indicate acculturation outcomes lately grouped them under two major categories namely: psychological outcomes and socio-cultural outcomes. Psychological outcomes mainly involves variables amongst other such as stress, coping, mental health and general satisfaction with life in the host environment. Socio-cultural outcomes mainly involve variables amongst other such as culture, learning tradition and are mainly a matter of successful participation in the host culture. Ward and Kennedy (1992) reported that socio-cultural outcomes relate to minority groups' participation and acceptance of the dominant group's surroundings. Berry (2003) argued that psychological outcomes and sociocultural outcomes are closely related; their correlations have been reported to be in the range of 0.4 and 0.5. This study will focus on the individuality of acculturation outcomes and their relationships. Different types of individual acculturation, for example integration, separation, assimilation, rejection and deculturation, have been studied. Integration refers to the process of successfully integrating aspects from both cultures. This has been empirically supported as the healthiest acculturation outcome (Cuellar \& Paniagua, 2000). Assimilation and integration preferences were highly correlated between psychological health and socio-cultural adaptation (Ward \& Rana-Deuba, 1999). Deculturation takes place when the individual accepts neither home culture nor the new culture.

\section{Psychological acculturation outcomes: III-health and Intentions to quit}

Bennett and Murphy (1997) defined health (physical and psychological) as a state of complete mental and social wellbeing and as a sense of wholeness and happiness on a physical, cultural, spiritual, and mental level. Research (Berry, 2003; Berry \& Sam, 1997) indicated that those minority groups who integrate are usually achieving the most encouraging outcomes as opposed to those who separate themselves. This result explains why minority group members are likely to experience less stress associated with acculturation, as they are psychologically better prepared for it. 
Parker, Chan and Tully (2006) concur with this by suggesting that minority members who do not integrate with the dominant group would more likely show signs of depression. Noh, Beiser, Kaspar, Hou, and Rummens, (1999) reported that it has been widely known that the experience of race discrimination indeed has a significant negative effect on a person's wellbeing. They also alluded to the fact that racism is the most serious factor facing minority groups and their mental health. Kessler et al., (1999) reported that everyday discrimination normally has a greater effect on one's mental health than major lifetime discrimination.

With regards to intentions to quit, It can be construed that those in the workplace are often triggered when the minority groups do not abide by or adapt to the dominant cultures. Intentions to quit can be seen as a psychological acculturation outcome indicator as they convey information about how well the individual feels in the acculturation context, and can be linked to education and length of stay of minority groups (Ward \& Kennedy, 1999).

\section{Contextualising the study}

No industries in the South African workplace are untouched by the socio-political changes, such as Broad-Based Black Economic Empowerment (BBBEE) and affirmative action, or the challenges faced by the South African society as a result of these changes. Although they have transformed the landscape of the South African workplace, issues such as racism and discrimination prevail (Smith, Stones, \& Naidoo, 2003) and are reported under news headlines such as "Employees of leading accounting firm KPMG are embroiled in a racial clash after a night of drinking at the company's action-cricket league finals" (Van Wyk, 2011) and "For the first time today I was able to feel what discrimination felt like when our payroll department phoned me to enquire what race I was" (David, 2011), "Recently a gender audit by the South African National Editors Forum found that white male journalist are paid more and hold more top positions in the South Africa's newsrooms" (Anonymous, 2011). Such alleged incidents are continual reminders that the challenges related to racism, discrimination and challenges in cultural contact remain prominent in various spheres of South African society, including the workplace. 
Given this reality, the study aimed at establishing the extent of employees in the workplace experiencing racism, discrimination, segregation and separation, and how these conditions influence employees' intentions to quit and their wellbeing. The goals of the study were to:

- investigate the associations between mainstream adverse conditions of racism, discrimination, segregation, ethnic separation, and wellbeing at work, as measured by ill-health and intentions to quit;

- determine the mediating effect of ethnic separation in the relationship between adverse acculturation conditions and wellbeing in the workplace

\section{RESEARCH METHOD}

This research method section considers the research design and procedure, sampling method used and participants, measuring instruments and statistical analysis used in the empirical phase.

\section{Research design and procedure}

The aim of the research design is to explain the approach the research will follow. The research design used is classified as quantitative. Welman, Kruger, and Mitchell, (2005) explain quantitative research as an array of interpretive techniques that seek to describe, decode, translate and otherwise come to terms with the meaning of naturally occurring phenomena in the social world. The specific methods used include questionnaires to gather information. Survey questionnaires were distributed to conveniently selected employees in various sectors of the workplace. These employees were mostly friends and acquaintances. In addition, permission was acquired through formal verbal requests to line managers to use other employees not acquainted with the researcher to fill out the questionnaires. In this verbal request the purpose of the research and its advantages were explained. Participants were given two days to complete the questionnaires, which were then collected by the researcher. 


\section{Participants}

Participants were selected from a convenient sample from different sectors in the workplace. The usefulness of this sampling technique is that it allows one to gather basic data and trends and is useful in identifying relationships among different phenomena. The participants were conveniently selected amongst the operational workers and middle management. Table 1 (below) represents some of the characteristics of the participants.

Table 1: Participant Characteristics

\begin{tabular}{llcc}
\hline Item Description & Category & Frequency & Percentage \\
\hline Gender & Male & 146 & 44.65 \\
Age & Female & 181 & 55.35 \\
& $18-25$ & 76 & 23.24 \\
& $26-33$ & 133 & 40.67 \\
& $34-41$ & 82 & 25.08 \\
Race & $42-49$ & 24 & 7.34 \\
& $50-60$ & 12 & 3.67 \\
& White & 77 & 23.55 \\
& Black & 109 & 33.33 \\
Coloured & 113 & 34.56 \\
& Indian & 26 & 7.95 \\
& Other & 2 & 0.61 \\
& Grade 12 & 101 & 30.89 \\
& Certificate & 74 & 22.63 \\
& Diploma & 82 & 25.08 \\
& Degree & 41 & 12.54 \\
& Postgraduate & 25 & 7.65 \\
\hline
\end{tabular}

The sample $(\mathrm{N}=327)$ consisted mainly of female employees $(55.35 \%)$, in the age range between 26 and 33 years $(40.67 \%)$, coloured $(34.56 \%)$ and holding a grade 12 or National Senior certificate $(30.89 \%)$. 


\section{Measuring instruments}

Some instruments with well-established psychometric properties used in other cultural contexts were adapted (Ait Ouarasse \& Van de Vijver, 2004). Adaptations involved replacing Dutch and Moroccans with South African and own ethnic group respectively. All acculturation scales follow a five-point Likert format ranging from strongly agree (1) to strongly disagree (5), and some item scores were reversed before the analyses so that higher scores reflect more endorsement of the underlying attitude.

\section{Mainstream domain instruments}

- Mainstream segregation demands (Ait Ouarasse \& Van de Vijver, 2004). This is a 12-item measure of the extent to which participants think that mainstream members hold segregationist attitudes towards minority members. A sample item is "I think that most of my fellow residents would be happy to have people from other cultures than their own to be thrown out of our organisation" $(\alpha=0,93)$.

- Perceived discrimination (Ait Ouarasse \& Van de Vijver, 2004). The scale is an 11 -item measure of the extent to which participants think the situation in the dormitory is discriminatory and requires them to drop their cultural characteristics. Discrimination refers to pressure exerted on the minorities to apply fully to the regulations and the general atmosphere regardless of whether these regulations encroach on minority sensitivities. The scale contains items such as "l experience discrimination in our organisation" $(\alpha=0,92)$.

- Subtle racism (Subtle Racism Scale of Duckitt, 1991). This is a 10-item (four of the items were filter items and were not used in the final analysis) measure of the extent to which co-workers hold subtle racist attitudes. A sample item includes "Some groups in South Africa are getting too demanding in pushing for equal rights" $(\alpha=0,89)$. 


\section{Ethnic domain instrument}

- Perceived co-ethnic separation demands at work (Ait Ouarasse \& Van de Vijver, 2004) is a four-item measure of the extent to which participants think their own ethnic members want them to keep away from the majority culture. Separation is a strategy aimed at the prevention of mainstream influence on minority ways. The scale contains items such as "My cultural group members do not want me to make contact with members from other cultural groups in our organisation" ( $\alpha=$ $0,80)$.

- Individual separation acculturation strategy. This new instrument is a three-item measure of the extent to which participants prefer contact with their own ethnic group members and do not seek participation in the 'Rainbow Nation' culture. The scale contains items such as "I actually avoid contact with members from other cultures" $(\alpha=0,70)$.

\section{Psychological acculturation outcomes}

- III Health: This is an adapted version of the 18 physical health symptoms of the PSI of Spector and Jex (1998), complimented with a list of 9 common psychological complaints based on a slightly modified version of the World Health Organisation Cross-National Survey of Psychological and Somatic Symptoms (1988). The scale employs a frequency format that ranges from never (1) to every day (5). The self-report measure asks respondents to indicate whether or not in the past three months they had suffered any of the mentioned symptoms. Some examples of symptoms included on the scale are headaches, backache, fatigue, eyestrain and trouble sleeping, concentrating and constant anxiety or panic attacks.

- Intentions to quit (develop for the study). This is a three-item measure of participants' intentions to quit their work. All of the items are positively phrased. It contains items pertaining to $(\alpha=0,88)$. 
A Biographical questionnaire was also included, dealing with basic biographical questions such as age, sex, and race.

\section{Data analysis}

The statistical analysis was completed with the help of the SPSS-programme (SPSS Inc., 2003). Descriptive statistics (e.g. means, standard deviations, skew and kurtosis) was used to scrutinize data. Cronbach alpha coefficients were used to determine the internal consistency, homogeneity and uni-dimensionality of the measuring instruments (Clark \& Watson, 1995). Coefficient alpha contains important information regarding the variance proportion of the items on a scale in terms of total variance explained by that particular scale.

Exploratory factor analyses were carried out to determine construct validity of the measuring instruments. Pearson product-moment correlation coefficients were used to specify the relationship between the variables in terms of statistical significance; we set the value at a 95\% confidence interval $(p<0,05)$. Effect sizes (Steyn, 1999) were used to decide on the practical significance of the findings. Pearson productmoment correlation coefficients were used to specify relationships between the variables. A cut-off point of 0,30 (medium effect, Cohen, 1988) was set for the practical significance of correlation coefficients. To investigate the mediating role of ethnic separation in the relations between adverse mainstream conditions and wellbeing, structural equation modelling (SEM-) was performed using AMOS 18 (Arbuckle, 2010).

\section{RESULTS}

The results of this study consist of three parts: (1) the descriptive statistics of measuring factors/variables; (2) correlation between positive acculturation conditions or characteristics, mediating variables and wellbeing (the acculturation psychological and socio-cultural outcomes as measured by physical and psychological ill-health and intentions to quit); and (3) the testing of the mediating role of ethnic separation in the relationship between the adverse acculturation antecedents and wellbeing amongst employees in the South African workplace. 


\section{Exploratory factor analyses and associations between antecedent conditions,}

intervening variables and wellbeing. Exploratory factor analyses were conducted first to confirm that the hypothesised items load on the factors or latent variables. Items with factor loadings higher than 0,30 were considered as sufficient descriptors of the latent variable. The results indicated that all scales used were uni-factorial; the first factor explained $56.60 \%$ of the variance in Perceived Mainstream Segregation Demands; $45.87 \%$ in Subtle Racism at Work; $60.33 \%$ in Perceived Discrimination at Work; $56.29 \%$ in Ethnic Separation Demands at Work; $62.48 \%$ in an Individual Separation Acculturation Strategy; $42.87 \%$ in Physical III-Health; $61.20 \%$ in Psychological III-Health; and $81.12 \%$ in Intentions to quit. The descriptive statistics of the various measuring instruments used in this study are presented in Table 2 (below).

Table 2: Descriptive Statistics $(n=327)$

\begin{tabular}{lccccc}
\hline \multicolumn{1}{c}{ Variable } & Mean & SD & Skew & Kurtosis & $\alpha$ \\
\hline 1. Segregation Demands & 2.29 & 0.80 & 0.27 & -0.70 & 0.93 \\
2. Perceived Discrimination & 2.64 & 0.88 & 0.03 & -0.44 & 0.92 \\
3. Subtle Racism & 2.57 & 0.76 & -0.08 & -0.63 & 0.89 \\
4. Ethnic Separation Demands & 2.40 & 0.85 & 0.10 & 2.54 & 0.80 \\
5. Individual Separation Strategy & 2.25 & 0.90 & 0.64 & -0.07 & 0.70 \\
6. Intentions to Quit & 2.63 & 1.09 & 0.23 & -0.67 & 0.88 \\
7. Physical Health & 1.93 & 0.72 & 0.91 & 0.18 & 0.93 \\
8. Psychological Health & 1.93 & 0.85 & 0.84 & -0.03 & 0.91 \\
\hline
\end{tabular}

Inspection of Table 2 shows that all the alpha coefficients were higher than the guideline of the alpha coefficient larger than 0,70 (Nunnally \& Bernstein, 1994) and that all scores were normally distributed. However, ethnic separation demands is a bit peak with a kurtosis of 2,54 implying that most of the responses were around the mean. Next, the relationship was determined between the different variables focused on in this study. The product-moment correlation coefficients between the different constructs used in this research project are reported in Table 3 (below). 
Table 3: Correlations between acculturation constructs and outcomes

\begin{tabular}{|l|c|c|c|c|c|c|c|}
\hline Variable & $\mathbf{1}$ & $\mathbf{2}$ & $\mathbf{3}$ & $\mathbf{4}$ & $\mathbf{5}$ & $\mathbf{6}$ & $\mathbf{7}$ \\
\hline 1 Segregation Demands & - & - & - & & - & - & - \\
\hline 2 Perceived Discrimination & $0.65^{* *}$ & - & - & & - & - & - \\
\hline 3 Subtle Racism & $0.64^{* *}$ & $0.75^{* *}$ & - & & - & - & - \\
\hline 4 Ethnic Separation Demands & $0.59^{* *}$ & $0.52^{* *}$ & $0.54^{* *}$ & - & & & \\
\hline 5 Individual Separation Strategy & $0.60^{* *}$ & $0.42^{* *}$ & $0.46^{* *}$ & $0.48^{* *}$ & - & - & - \\
\hline 6 Intentions to Quit & $0.12^{*}$ & $0.14^{*}$ & $0.18^{* *}$ & $0.17^{* *}$ & $0.17^{* *}$ & - & - \\
\hline 7 Physical Health & $0.21^{* *}$ & $0.17^{* *}$ & $0.20^{* *}$ & $0.24^{* *}$ & $0.12^{*}$ & $0.19^{* *}$ & - \\
\hline 8 Psychological Health & $0.28^{* *}$ & $0.16^{* *}$ & $0.20^{* *}$ & $0.26^{* *}$ & $0.23^{* *}$ & $0.22^{* *}$ & $0.71^{* *}$ \\
\hline
\end{tabular}

${ }^{\star *}$ Correlation is significant at the $\mathrm{P}<0.01$ level $/{ }^{*}$ Correlation is significant at the $\mathrm{P}<0.05$ level

Inspection of Table 3 revealed that Segregation demands are statistically and significantly correlated to perceived discrimination (with a large effect), subtle racism (with a large effect), ethnic separation demands (with a large effect), and individual separation strategy (with a large effect). Perceived Discrimination is statistically and significantly correlated to subtle racism (with a large effect), ethnic separation demands (with a large effect), and individual separation strategy (with a medium effect). Subtle Racism is statistically and significantly correlated to ethnic separation demands (with a large effect) and individual separation strategy (with a medium effect). Physical health is statistically and significantly correlated to psychological health (with a large effect).

\section{A model testing the mediation effect of separation in the relation between} mainstream conditions and wellbeing. In this hypothetical model three perceived adverse mainstream attitudes (segregation demands, discrimination and subtle racism at work) are antecedent conditions that impact on a single latent variable (wellbeing at work) that is measured using three indicators, namely physical and psychological ill-health and intentions to quit (psychological acculturation outcomes) through a mediating latent variable (involving ethnic separation) that is measured by two indicators, namely ethnic integration demands at work and an individual separation acculturation strategy. We used various indices to assess the goodness of fit of the model. 
The structural equation model analysis (see Figure 1) yielded an acceptable fit: $\mathrm{X}^{2}(15, N=327)=22.68, p=<0.09 ; \mathrm{X}^{2} / d f=1.51$ [the $\mathrm{X}^{2} / \mathrm{df}$ (recommended value in small samples, < 3), the adjusted goodness of fit index (AGFI) was .96 (recommended, $\geq .90$ ), the Tucker Lewis index (TLI) was .99 (recommended, $\geq .90$ ), the comparative of fit index (CFI) was .99 (recommended, $\geq 0.90$ ), and the root mean square error of approximation (RMSEA) was .04 (recommended, s.05). The acceptable fit of the empirical data to the conceptual model indicates that mainstream acculturation conditions are associated with wellbeing at work as measured with three indicators, namely physical and psychological ill-health and intentions to quit through separation as the intervening variable.

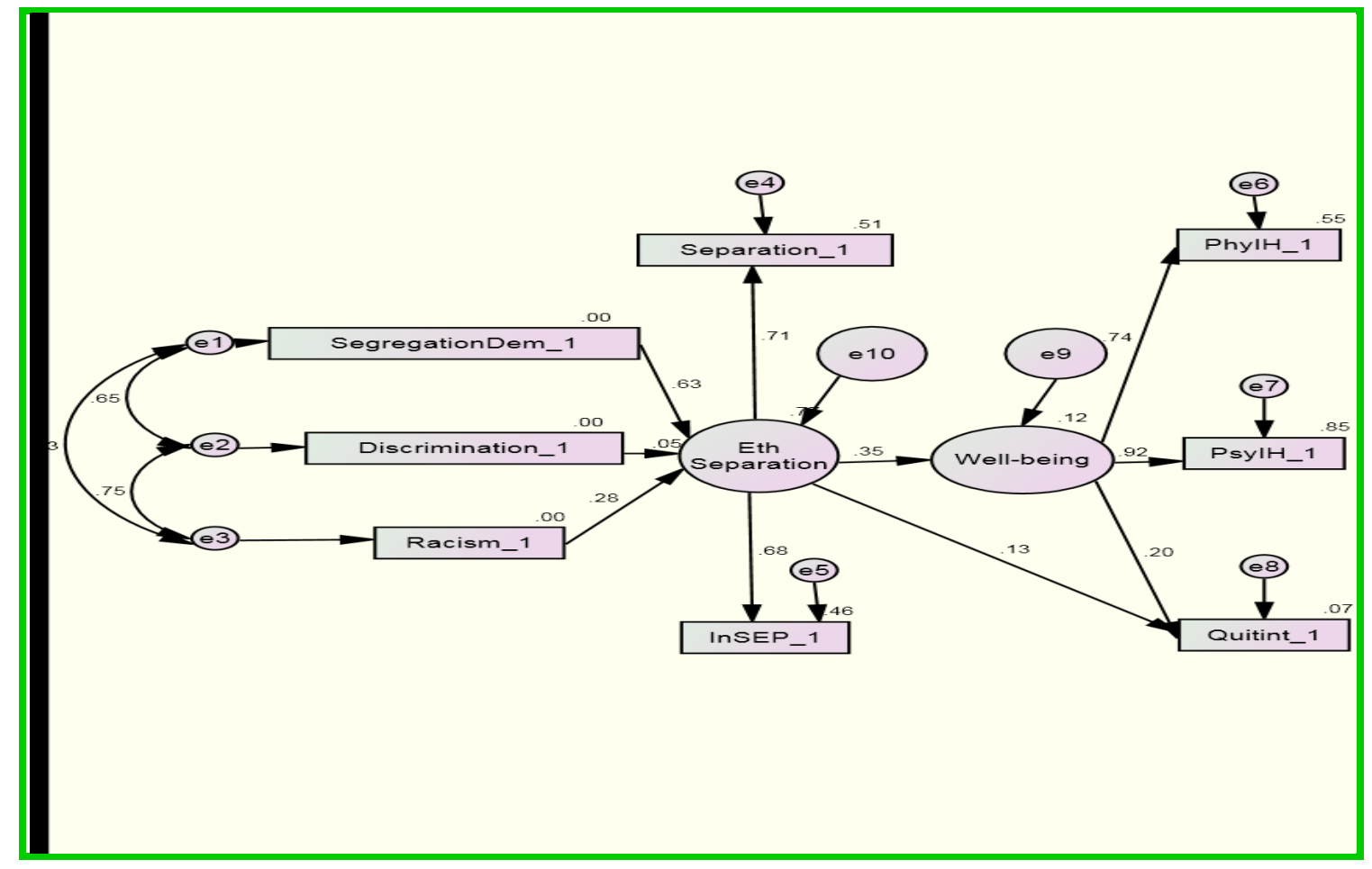

Figure 1: Results of the Mediating Acculturation Model Analysis

Figure 1 (above) indicated that the paths from mainstream segregation demands and subtle racism to ethnic separation were significant, with mainstream segregation demands yielding the strongest association with ethnic separation compared to the other mainstream adverse conditions and ethnic separation. In addition, the path from ethnic separation to wellbeing at work was also significant. This finding suggests that a perceived mainstream segregation demands and subtle racism are related to wellbeing at work in this sample. 
Employees who experience a more perceived mainstream segregation demands and subtle racism at work also reported better wellbeing at work. We can therefore conclude that perceived mainstream segregation demands and subtle racism are significant factors in wellbeing at work.

Mediating effects of ethnic separation: The hypothesized model is a mediation model in which adverse antecedent conditions influence ethnic separation, which in turn impact on wellbeing of workers. We made a closer examination of the direct and indirect effects to evaluate their relative sizes. There is some literature on the testing of mediation effect (e.g., Baron \& Kenny, 1986; Holmbeck, 1997; Hoyle \& Kenny, 1999; Judd \& Kenny, 1981; Kline, 1998; Preacher \& Hayes, 2004).

It has been found that the method proposed by Baron and Kenny (1986) can have a low statistical power in most situations and that joint significance tests involving the product of coefficients have been found to have greater statistical power than that of other formal methods of assessing mediation, including the Baron and Kenny approach (MacKinnon, Lockwood, Hoffman, West, \& Sheets, 2002). Therefore, we stayed within the structural equation framework to compute the significance of mediation effects by using the bootstrap procedure as implemented in the AMOS programme. The results of the mediation analysis can be found in Table 3 (below).

Table 4: Mediation Effects of Separation in the Workplace (Standardized Effects)

\begin{tabular}{|l|ccc|ccc|ccc|}
\hline & \multicolumn{3}{|c|}{ Physical III-health } & \multicolumn{3}{c|}{ Psychological III-health } & \multicolumn{3}{c|}{ Intentions to Quit } \\
Predictor & Direct & Indirect & Total & Direct & Indirect & Total & Direct & Indirect & Total \\
\hline Segregation & 0.00 & 0.17 & $0.17^{*}$ & 0.00 & 0.21 & 0.21 & 0.00 & 0.12 & 0.12 \\
Subtle Racism & 0.00 & $0.07^{*}$ & $0.07^{*}$ & 0.00 & $0.09^{*}$ & $0.09^{*}$ & 0.00 & $0.06^{*}$ & $0.06^{*}$ \\
Discrimination & 0.00 & 0.01 & 0.01 & 0.00 & 0.01 & 0.01 & 0.00 & 0.01 & 0.01 \\
Ethnic & 0.00 & $0.26^{*}$ & $0.26^{*}$ & 0.00 & $0.32^{*}$ & $0.32^{*}$ & 0.13 & $0.07^{*}$ & $0.20^{*}$ \\
Separation & & & & & & & & & \\
\hline
\end{tabular}

Note. ${ }^{* *}$ effects are significant $(p<.01) /{ }^{*}$ effects are significant $(p<.05)$

Closer inspection of Table 4 indicated that in line with observations from Figure 1, total and indirect effects were observed for physical and psychological ill-health as well as intentions to quit. 
In addition, the insignificance of all direct affects suggests that the link with physical and psychological ill-health as well as intentions to quit are fully mediated by ethnic separation. Mainstream segregation demands and subtle racism have, therefore, indirect and significant influence on psychological acculturation outcomes (physical and psychological ill-health as well as intentions to quit). It can be concluded that ethnic separation fully mediates the path from mainstream segregation demands and subtle racism to psychological acculturation outcomes and that mainstream segregation demands and subtle racism matter for the experience of wellbeing at work.

\section{DISCUSSION}

The aim of the study was to determine the relationships between adverse acculturation conditions (pressure to segregate and overt and covert discrimination), separation attitudes, and wellbeing at work. Adverse mainstream conditions were positively related to ethnic separation demands and work and an individual separation strategy, ill-health and intentions to quit. This implies that a work environment characterised by more mainstream segregation, discrimination and subtle racism is more likely to contribute to ethnic members encouraging each other to separate and limited mainstream contact as well as higher levels of ill-health symptoms and frequent thoughts of intentions to quit. Our finding seems to concur with previous consistent links between perceived racism, discrimination, and poor psychological outcomes (Clark, Anderson, Clark, \& Williams, 1999; Gee, Ro, ShariffMarco, \& Chae, 2009).

The study also tested the association between acculturation mainstream antecedent conditions and wellbeing through separation as a latent mediating ethnic variable. The hypothesised model was confirmed in a structural equation modelling analysis. This means that more mainstream segregation demands and subtle racism, coupled with a dominant ethnic separation acculturation strategy and co-ethnics demanding that their members keep to themselves at work (with limited or no intercultural contact), are associated with the experience of higher physical and psychological illhealth and frequent thoughts of intentions to quit. 
In addition, mainstream segregation demands, compared to subtle racism and discrimination, were much more strongly associated with ethnic preference to separate. This result supports the positive relations found (Berry et al., 2006; Heim, Hunter, \& Jones, 2010; Jackson et al., 2011) between negative acculturation conditions, separation and ill-health as well as the importance of taking both the mainstream and ethnic conditions into consideration in acculturation studies, as recommended by the Integrated Acculturation Model (Bourhis, 1997). It therefore seems likely that a workplace culture that promotes ethnic cultural separation coupled with encouragement by ethnic members at work contributes to the experience of higher levels of ill-health symptoms (Jackson et al., 2011).

The study also focussed on the mediating effect of the separation in the path from adverse antecedent variables to wellbeing, as measured by ill-health symptoms and intentions to quit. Our findings suggest an indirect and significant influence of adverse conditions (excluding discrimination) on physical and psychological ill-health symptoms and intentions to quit. It could, therefore, be concluded that separation mediates the path from mainstream segregation demands and subtle racism to physical and psychological ill-health symptoms and intentions to quit. It can be concluded that separation demands fully mediate the path from mainstream segregation demands and subtle racism to psychological acculturation outcomes at work, and that mainstream adverse conditions matter for the experience of wellbeing at work. Our findings are in line with a recent review of discrimination and health that suggests that racism precedes, rather than follows negative mental health outcomes and health-related behaviours (Gee et al., 2009; Jackson et al., 2011).

The main limitations of the study involve the limited sample size and the crosssectional design used. Future studies could consider specific industries with larger sample sizes as well as longitudinal design to firmly establish cause and effect as well as the impact of the issues covered as well other issues of relevance for sound race relations in South Africa.

In the light of recent racial polarisation in South Africa, future research could consider the experience of Indians as well as various immigrant groups in the workplace of the "New" South Africa. 


\section{REFERENCES}

Ait Ouarasse, O. \& Van de Vijver, F. J. R. (2004). Structure and function of the perceived acculturation context of young Moroccans in the Netherlands. International Journal of Psychology, 39(3):90-204

Anonymous, (2007). Workplace discrimination 'rife'. Retrieved November 30, 2011, from http://www.news24.com/

Arbuckle, J. L. (2010). Amos 18. Chicago, IL: Smallwaters.

Ayalon, L. \& Gum, A.M. (2011). The relationships between major lifetime discrimination, everyday discrimination, and mental health in three racial and ethnic groups of older adults. Department of Aging and Mental Health Disparities, University of South Florida, Vol. 15, No. 5, July 2011, 587-594

Bennett, P., \& Murphy, S. (1997). Psychology and health promotion. Buckingham: Open University Press.

Barrette, G., Bourhis, R.Y., Personnaz, M., \& Personnaz, B. (2004). Acculturation orientations of French and North African undergraduates in Paris. International Journal of Intercultural Relations, 28(5):415-438

Baron, R. M., \& Kenny, D. A. (1986). The moderator-mediator variable distinction in social psychological research: Conceptual, strategic, and statistical considerations. Journal of Personality \& Social Psychology, 51:1173-1182.

Berry, J.W., \& Kim, U. (1988). Acculturation and mental health. In P .R. Dasen, J.W. Berry, \& N. Sartorius (Eds). Health and cross-cultural psychology: Towards applications (pp.207-236). Newbury Park, CA: Sage.

Berry, J. W., \& Sam, D. L. (1997). Acculturation and adaptation. In J. W. Berry, M. H. Segall, C. Kagitcibasi (Eds.), Handbook of cross-cultural psychology: Social behaviour and applications (2nd ed.. Vol 3, pp. 291-326). Boston, MA: Allyn \& Bacon.

Berry, J. W. (2001). A psychology of immigration. Journal of Social Issues, $57(3): 615-6331$

Berry, J. W. (2003). Conceptual approaches to acculturation. In K. M. Chun, P. B. Organista \& G. Marin (Eds.), Acculturation: Advances in theory, measurement, and applied research (pp.17-39). Washington, DC: American Psychological Association.

Berry, J.W., Phinney, J.S., Sam, D.L., \& Vedder, P. (Eds.). (2006). Immigrant youth in cultural transition: Acculturation, identity and adaptation across national contexts. Mahwah, NJ: Lawrence Erlbaum Associates. 
Bourhis, R. Y. (1997). Toward an Integrative Acculturation Model: A social psychological approach. International Journal of Psychology, 32(6):369-38

Bhorat, H. \& Kanbur, R. (2006). Poverty and Policy in Post-Apartheid South Africa Retrieved 20 November 2011, from www.hsrcpress.ac.za

Broman, C. L. (1996). "The Health Consequences of Racial Discrimination: A Study of African Americans." Ethnicity and Disease 6:148-53.

Cuellar, I. \& Paniagua F. A. (2000). Handbook of Multicultural Mental Health. San Diego, California, Academic Press.

Clark, R., Anderson, N. B., Clark, V.R., \& Williams, D.R. (1999).Racism as a stressor for African Americans: A biopsychosocial model. American Psychologist, 54:805-816

Clark, L. A., \& Watson, D. (1995). Constructing validity: Basic issues in objective scale development. Psychological Assessment, 7(3):309-319

Cohen, J. (1988). Statistical power analysis for the behavioural sciences (2nd ed.) Orlando, FL: Academic Press.

Christopher, A. J. (2001). Urban segregation in post-apartheid South Africa. Urban Studies, 38(3), 449-466.

Dahlberg, M., Fredriksson, P. Monseny, J.J. (2010). On the dynamics of segregation. Universitat de Barcelona.

David, (2011). Culture of Discrimination. Retrieved November 30, 2011, from http://www.news24.com/

Deitch, A. A., Barsky, A., Butz, R. M., Chan, S., Brief, A. P., \& Bradley, J. C. (2003). Subtle yet significant: The existence Acculturation and Wellbeing and impact of everyday racial discrimination in the workplace. Human Relation, 56(11), 12991324.

Dovidio, J. F,. \& Gaertner, S. L. (2000 Jul). Aversive racism and selection decisions: 1989 and 1999. Psychological Science, 11:315-319

Duckitt, J. (1991). The development and validation of a subtle racism scale in South Africa. South African Journal of Psychology, 21:233-239.

Durrheim, K. Baillie, K. \& Johnstone, L. (2006). The development and validation of a measure of racial justice perceptions. South African Journal of Psychology, 38(4):615-632.

Feagin, J.R. (1991). "The Continuing Significance of Race: Antiblack Discrimination in Public Places, "American Sociological Review, 56(1):101-16. 
Feagin, J.R. and Heman, V. (1995). White Racism: The Basics. New York: Routledge.

Fisher, C. B., Wallace, S. A., \& Fenton, R. E. (2000). Discrimination distress during adolescence. Journal of Youth and Adolescence, 29(6):679-695.

Friedman, S. (2000). Racism under scrutiny. Weekly Mail \& Guardian

Gee, G. C., Ro, A, Shariff-Marco, S., \& Chae, D. (2009). Racial discrimination and health among Asian Americans: Evidence, assessment, and directions for future research. Epidemiologic Reviews, 1-22.

Graves, T. D. (1967). Psychological acculturation in a tri-ethnic community. South Western Journal of Anthropology, 23(4):336-350.

Heaven, P. C. L. \& Moerdyk, A. (1977). Prejudice revisited: A pilot study using Ray's scale. Journal of Behavioural Science, 2:217-220.

Heim, D., Hunter, S.C., \& Jones, R. (2010). Perceived discrimination, Identification, Social capital, and wellbeing: Relationships with physical and psychological distress in a U.K. minority ethnic community sample. Journal of Cross-Cultural Psychology: Dol: 10.1177/0022022110383310.

Hodson, G., Dovidio, J. F., \& Gaertner, S. L. (2002). Processes in racial discrimination: Differential weighting of conflicting information. Personality and Social Psychology Bulletin, 28(4):460-471.

Hofmeyr, J.H. (2006, November). Report of the Sixth Round of the SA Reconciliation Barometer Survey. Wynberg: Institute for Justice and Reconciliation

Holmbeck, G. N. (1997). Toward terminological, conceptual, and statistical clarity in the study of mediators and moderators: Examples from the child-clinical and pediatric psychology literatures. Journal of Consulting \& Clinical Psychology, 65:599-610.

Hoyle, R. H., \& Kenny, D. A. (1999). Sample size, reliability, and tests of statistical mediation. In R. Hoyle (Ed.), Statistical strategies for small sample research (pp. 195-222). Thousand Oaks, CA: Sage.

Jackson L.T.B., Van de Vijver F.J.R., Burckard A., (2011). Adverse Acculturation Conditions and Wellbeing of Mine Employees in the North-West Province. Journal of Psychology in Africa, 21(3):385-396

Judd, C. M., \& Kenny, D. A. (1981). Process analysis: Estimating mediation in treatment evaluations. Evaluation Review, 5:602-619.

Kessler, R.C., Mickelson, K.D., \& Williams, D.R., (1999). The prevalence, distribution, and mental health correlates of perceived discrimination in the United States. Journal of Health and Social Behavior, 40:208-230. 
Kline, R. B. (1998). Principles and practice of structural equation modelling. New York, NY: Guilford.

MacKinnon, D. P., Lockwood, C. M., Hoffman, J. M., West, S. G., \& Sheets, V. (2002). A comparison of methods to test mediation and other intervening variable effects. Psychological Methods, 7:83-104.

Marisol, N. Antonio, J. R., Garcia, M., Pumares, P.. (2007). Acculturation strategies and attitudes according to the Relative Acculturation Extended Model (RAEM), The perspectives of natives versus immigrants. International Journal of Intercultural Relations; Science Direct, 30(5).

Mallinckrodt, B., \& Leong , F. T. (1992). International graduate students, stress, and social support. Journal of College Student Development, 33:71-78.

Moomal H. Jackson, P.B., Stein, D.J., Herman, A., Myer, L., Seedat, S., MadelaMntla, E., Williams D.R., (2009) Perceived discrimination and mental health disorders, The South African Stress and Health study. May 2009, Vol. 99, No. 5 SAMJ.

Noh, S., Beiser, M., Kaspar, V., Hou, F., \& Rummens, J. (1999). Perceived racial discrimination, depression and coping. Journal of Health and Social Behaviour, 40(3):93 -207.

Nunnally, J. C, \& Bernstein, I. H. (1994). Psychometric theory (3rd edition). New York: McGraw-Hill.

Ong, A. D., Fuller-Rowell, T., \& Burrow, A. L. (2009). Racial discrimination and the stress process. Journal of Personality and Social Psychology, 96:1259-1271.

Pavalko, E.K., Mossakowski, K.N., \& Hamilton, V.J. (2003). Does Perceived discrimination Affect Health? Longitudinal Relationships between Work Discrimination and Women's Physical and Emotional Health. Journal of Health and Social Behavior 2003, 43 (March):18-33.

Parker, G., Chan, B., and Tully, L. (2006). "Recognition of Depressive Symptoms by Chinese Subjects: the Influence of Acculturation and Depressive Experience." Journal of Affective Disorders.

Pham, T.B., \& Harris, R.J. (2001). Acculturation strategies among VietnameseAmericans. International Journal of Intercultural Relations, 25(3), 279-300.

Phinney, J.S. (1990). Ethnic identification in adolescence and adulthood: $A$ review and integration. Psychological Bulletin, 108(3):499-514.

Phinney, J.S. (1995). Ethnic identity and self-esteem: A review and integration. In A.M. Padilla (Ed.), Hispanic psychology: Critical issues in theory and research (pp. 57-70). Thousand Oaks, CA: Sage. 
Preacher, K. J., \& Hayes, A. F. (2004). SPSS and SAS procedures for estimating indirect effects in simple mediation models. Behavior Research Methods, Instruments, \& Computers,36, 717-731.

Roscigno V.J. (2007). The Face of Discrimination: How Race and Gender Impact Work and Home Lives. Rowman \& Littlefield. Social Forces 7(4).

SPSS, Inc. (2003). SPSS 12.0 for Windows. Chicago, IL: SPSS

Spector, P. E., \& Jex, S. M. (1998). Development of four self-report measures of job stressors and strain: Interpersonal conflict and work scale, quantitative workload inventory. Journal of Occupational Health Psychology, 3(4):356-367.

Smith, T. B., Stones, C. R., \& Naidoo, A. (2003). Racial attitudes among South African young adults: A four year follow-up study. South African Journal of Psychology, 33(1):39-43.

Steyn, H. S., Jr. (1999). Praktiese beduidendheid: die gebruik van effekgroottes [Practical significance: The use of effect sizes]. Wetenskaplike bydraes, Reeks B: Natuurwetenskappe nr. 117, Potchefstroomse Universiteit vir $\mathrm{CHO}$, Potchefstroom.

Swim, J. K., Aikin, K. J., Hall, W. S., \& Hunter, B. A. (1995). Sexism and racism: Old fashioned and modern prejudices. Journal of Personality and Social Psychology, 68(2):199-214.

Vedder, P., Van de Vijver, F. J. R., \& Liebkind, K. (2006). Predicting immigrant youths adaptation across countries and ethnocultural groups. In J. W. Berry, J. S. Phinney, D. L. Sam, \& P. Vedder (Eds.), Immigrant youth in cultural transition: Acculturation, identity and adaptation across national contexts (pp. 143-166). Mahwah, NJ: Erlbaum.

Van Wyk, E., (2011). Alleged racial attack just not cricket. Retrieved November 30, 2011, from http://www.news24.com/.

Vernellia, R. (2008). Defining Race Racism and Racial Discrimination. Retrieved November 02, 2011, from http://academic.udayton.edu/race/01race/race08.htm

Ward, C, \& Kennedy, (1992). Locus of control, mood disturbance, and social difficulty during cross-cultural transitions. International Journal of Intercultural Relations, 16(2):175-194.

Ward, C, \& Kennedy, A (1999). The measurement of sociocultural adaptation. International Journal of Inter cultural Relations, 23(4):659-677.

Ward C., \& Rana-Deuba, A. (1999). Acculturation and adaptation revisited. Journal of Cross-Cultural Psychology, 30(4):372-392. 
Ward, C. (2001). The A, B, Cs of acculturation. In D. R. Matsumoto (Ed.), The handbook of culture and psychology (pp. 411-445). San Francisco: Oxford University Press.

Ward, C, Bochner, S., \& Furnham, A. (2001). The psychology of culture shock. London: Routledge.

Welman, C., Kruger, F., \& Mitchell, B., (2005). Research Methodology (3 ${ }^{\text {rd }}$ ed). Oxford Southern Africa. University Press.

World Health Organization. (1988). World Health Organization cross-national survey of psychological and somatic symptoms, Geneva, Switzerland.

Zagefka, H., \& Brown, R. (2002). The relationship between acculturation strategies, relative fit and intergroup relations: Immigration-majority relations in Germany. European Journal of Social Psychology, 32(2):171-188. 


\section{CHAPTER 3}

\subsection{CONCLUSIONS}

The aim of the study was to determine the relationships between adverse acculturation conditions (pressure to segregate and overt and covert discrimination), separation attitudes, and wellbeing at work. Adverse mainstream conditions were positively related to ethnic separation demands and work and an individual separation strategy, ill-health and intentions to quit. This implies that a work environment characterised by more mainstream segregation, discrimination and subtle racism is more likely to contribute to ethnic members encouraging each other to separate and limited mainstream contact as well as higher levels of ill-health symptoms and frequent thoughts of intentions to quit. Our finding seems to concur with previous consistent links between perceived racism, discrimination, and poor psychological outcomes (Clark, Anderson, Clark, \& Williams, 1999; Gee, Ro, ShariffMarco, \& Chae, 2009).

The study also tested the association between acculturation mainstream antecedent conditions and wellbeing through separation as a latent mediating ethnic variable. The hypothesised model was confirmed in a structural equation modelling analysis. This means that more mainstream segregation demands, discrimination, and subtle racism coupled with a dominant ethnic separation acculturation strategy and coethnics demanding that their members keep to themselves at work (with limited or no intercultural contact), are associated with to the experience of higher physical and psychological ill-health and frequent thoughts of intentions to quit. In addition, mainstream segregation demands, compared to subtle racism and discrimination, were much more strongly associated with ethnic preference to separate. This result supports the positive relations found (Berry, 2006; Heim, Hunter, \& Jones, 2010; Jackson et al, 2011) between negative acculturation conditions, separation and illhealth as well as the importance of taking both the mainstream and ethnic conditions in consideration in acculturation studies, as recommended by the Integrated Acculturation Model (Bourhis, 1997). 
It therefore seems likely that a workplace culture that promotes ethnic cultural separation coupled with encouragement by ethnic members at work contributes to the experience of higher levels of ill-health symptoms (Jackson et al, 2011).

The study also focused on the mediating effect of the separation in the path from adverse antecedent variables to wellbeing as measured by ill-health symptoms and intentions to quit. Our findings suggest there is an indirect and significant influence of adverse conditions (excluding discrimination) on physical and psychological ill-health symptoms and intentions to quit. It could, therefore, be concluded that separation mediates the path from mainstream segregation demands and subtle racism to physical and psychological ill-health symptoms and intentions to quit. It can be concluded that separation demands fully mediate the path from mainstream segregation demands and subtle racism to psychological acculturation outcomes at work and that mainstream adverse conditions matter for the experience of wellbeing at work. Our findings are in line with a recent review of discrimination and health that suggests that racism precedes, rather than follows negative mental health outcomes and health-related behaviours (Gee et al, 2009; Jackson et al, 2011).

\subsection{RECOMMENDATIONS}

Future acculturation research that is recommended to be conducted includes supplementary studies to endeavour to compare different cultural group experiences of racism or discrimination as well as the mediating role of other acculturation strategy in the relationship between adverse conditions and wellbeing.

Many tools, interventions and methods are available to ensure that racism and discrimination do not impact negatively on people's health at work. Key recommendations to curb the situation include:

- Ensure that the organisation has clearly articulated policies regarding workplace discrimination in whatever form and that it is supported at the highest level. 
- Educate staff and managers with regard to the legal and organizational policies and procedures, as well as consciousness-raising and sensitisation regarding stereotypes and offensive behaviour.

- Ensure that procedures exist for staff to report discrimination and to receive support and assistance.

- Ensure that there are formal, effective structures in place to investigate and act on accusations of discrimination.

\subsection{LIMITATIONS}

The main limitations of the study involve the limited sample size and the crosssectional design used. Future studies could consider specific industries with larger sample sizes as well as longitudinal design to firmly establish cause and effect as well as the impact of the issues covered as well other issues of relevance for sound race relations in South Africa. In the light of recent racial polarisation in South Africa, future research could consider the experience of Indians as well as various immigrant groups in the workplace of the "New" South Africa.

Another limitation was that the questionnaire was only in English. The impact of this was that English was not first language of all participants, therefore there was a risk that questions could have been understood wrongly. 


\section{BIBLIOGRAPHY}

Ait Ouarasse, O., \& Van de Vijver, F. J. R. (2004). Structure and function of the perceived acculturation context of young Moroccans in the Netherlands. International Journal of Psychology, 39(3):90-204

Ali, S. (2008). Positive acculturation context variables as predictors of acculturation outcomes in a mine in the North West province (Master's thesis, North West University, Potchefstroom). Retrieved from http://dspace.nwu.ac.za/bitstream/10394/2037/1/vanderwesthuizen_henriette\% $281 \% 29$.pdf.

Anonymous, (2007). Workplace discrimination 'rife'. Retrieved November 30, 2011, from http://www.news24.com/

Arbuckle, J. L. (2010). Amos 18. Chicago, IL: Smallwaters.

Ayalon, L. \& Gum, A.M. (2011). The relationships between major lifetime discrimination, everyday discrimination, and mental health in three racial and ethnic groups of older adults. Department of Aging and Mental Health Disparities, University of South Florida, Vol. 15, No. 5, July 2011, 587-594

Bennett, P., \& Murphy, S. (1997). Psychology and health promotion. Buckingham: Open University Press.

Barrette, G., Bourhis, R.Y., Personnaz, M., \& Personnaz, B. (2004). Acculturation orientations of French and North African undergraduates in Paris. International Journal of Intercultural Relations, 28(5):415-438

Baron, R. M., \& Kenny, D. A. (1986). The moderator-mediator variable distinction in social psychological research: Conceptual, strategic, and statistical considerations. Journal of Personality \& Social Psychology, 51:1173-1182.

Berry, J.W., \& Kim, U. (1988). Acculturation and mental health. In P .R. Dasen, J.W. Berry, \& N. Sartorius (Eds). Health and cross-cultural psychology: Towards applications (pp.207-236). Newbury Park, CA: Sage.

Berry, J. W., \& Kalin, R. (1995). Multicultural and ethnic attitudes in Canada: An overview of the 1991 national survey. Canadian Journal of Behavioural Sciences, 27:301-320

Berry, J. W., \& Sam, D. L. (1997). Acculturation and adaptation. In J. W. Berry, M. H. Segall, C. Kagitcibasi (Eds.), Handbook of cross-cultural psychology: Social behaviour and applications (2nd ed. Vol 3, pp. 291-326). Boston, MA: Allyn \& Bacon.

Berry, J. W. (2001). A psychology of immigration. Journal of Social Issues, $57(3): 615-6331$ 
Berry, J. W. (2003). Conceptual approaches to acculturation. In K. M. Chun, P. B. Organista \& G. Marin (Eds.), Acculturation: Advances in theory, measurement, and applied research (pp.17-39). Washington, DC: American Psychological Association.

Berry, J.W., Phinney, J.S., Sam, D.L., \& Vedder, P. (Eds.). (2006). Immigrant youth in cultural transition: Acculturation, identity and adaptation across national contexts. Mahwah, NJ: Lawrence Erlbaum Associates.

Bourhis, R. Y. (1997). Toward an Integrative Acculturation Model: A social psychological approach. International Journal of Psychology, 32(6):369-38

Bhorat, H. \& Kanbur, R. (2006) Poverty and Policy in Post-Apartheid South Africa Retrieved 20 November 2011, from www.hsrcpress.ac.za

Broman, C. L. (1996) "The Health Consequences of Racial Discrimination: A Study of African Americans," Ethnicity and Disease 6:148-53.

Cuellar, I. \& Paniagua F. A. (2000). Handbook of Multicultural Mental Health. San Diego, California, Academic Press.

Clark, R., Anderson, N. B., Clark, V.R., \& Williams, D.R. (1999). Racism as a stressor for African Americans: A biopsychosocial model. American Psychologist, 54: 805-816

Clark, L. A., \& Watson, D. (1995). Constructing validity: Basic issues in objective scale development. Psychological Assessment., 7(3):309-319

Cohen, J. (1988). Statistical power analysis for the behavioural sciences (2nd ed.) Orlando, FL: Academic Press.

Christopher, A. J. (2001). Urban segregation in post-apartheid South Africa. Urban Studies, 38(3), 449-466.

Dahlberg, M., Fredriksson, P. Monseny, J.J. (2010) On the dynamics of segregation. Universitat de Barcelona.

David, (2011). Culture of Discrimination. Retrieved November 30, 2011, from http://www.news24.com/

Deitch, A. A., Barsky, A., Butz, R. M., Chan, S., Brief, A. P., \& Bradley, J. C. (2003). Subtle yet significant: The existence Acculturation and Wellbeing 393 and impact of everyday racial discrimination in the workplace. Human Relation, 56(11):1299-1324.

Devine, J. (2008). History of Discrimination. Retrieved March 04, 2011, from http://ezinearticles.com/?History-of-Discrimination\&id=1611512. 
Dovidio, J. F,. \& Gaertner, S. L. (2000 Jul). Aversive racism and selection decisions: 1989 and 1999. Psychological Science. 11:315-319

Duckitt, J. (1991). The development and validation of a subtle racism scale in South Africa. South African Journal of Psychology, 21:233-239.

Durrheim, K. Baillie, K. \& Johnstone, L. (2006). The development and validation of a measure of racial justice perceptions. South African Journal of Psychology, 38(4):615-632.

D'Souza, D. (2009). Causes of Discrimination. Retrieved March 19, 2010, from www.bookrags.co.za.

Elizabeth, H. \& Christopher J. L. (2010). Perceiving Discrimination on the Job: Legal Consciousness, Workplace Context, and the Construction of Race Discrimination. Retrieved March 19, 2011, from http://onlinelibrary.wiley.com.

Feagin, J.R., 1991, "The Continuing Significance of Race: Antiblack Discrimination in Public Places," American Sociological Review 56(1), 101-16.

Feagin, J.R., and Heman, V., 1995, White Racism: The Basics. New York: Routledge.

Feagan, J.R. \& Melvyn, P.S. (2009). Causes of Discrimination. Retrieved March 19, 2010, from www.bookrags.co.za

Fisher, C. B., Wallace, S. A., \& Fenton, R. E. (2000). Discrimination distress during adolescence. Journal of Youth and Adolescence, 29(6):679-695.

Friedman, S. (2000). Racism under scrutiny. Weekly Mail \& Guardian

Gee, G. C., Ro, A, Shariff-Marco, S., \& Chae, D. (2009). Racial discrimination and health among Asian Americans: Evidence, assessment, and directions for future research. Epidemiologic Reviews, 1-22.

Graves, T. D. (1967). Psychological acculturation in a tri-ethnic community. South Western Journal of Anthropology, 23(4):336-350.

Halpern, D. (1993). Minorities and mental health. Social Science and Medicine, 36, $597-60$

Heaven, P. C. L., \& Moerdyk, A. (1977). Prejudice revisited: A pilot study using Ray's scale. Journal of Behavioural Science, 2: 217-220.

Heim, D., Hunter, S.C., \& Jones, R. (2010). Perceived discrimination, Identification, Social capital, and wellbeing: Relationships with physical and psychological distress in a U.K. minority ethnic community sample. Journal of Cross-Cultural Psychology: Dol: 10.1177/0022022110383310. 
Hodson, G., Dovidio, J. F., \& Gaertner, S. L. (2002). Processes in racial discrimination: Differential weighting of conflicting information. Personality and Social Psychology Bulletin, 28(4):460-471.

Hofmeyr, J.H. (2006, November). Report of the Sixth Round of the SA Reconciliation Barometer Survey. Wynberg: Institute for Justice and Reconciliation

Holmbeck, G. N. (1997). Toward terminological, conceptual, and statistical clarity in the study of mediators and moderators: Examples from the child-clinical and pediatric psychology literatures. Journal of Consulting \& Clinical Psychology, 65:599-610.

Hoyle, R. H., \& Kenny, D. A. (1999). Sample size, reliability, and tests of statistical mediation. In R. Hoyle (Ed.), Statistical strategies for small sample research (pp. 195-222). Thousand Oaks, CA: Sage.

Jackson L.T.B., Van de Vijver F.J.R., Burckard A., (2011). Adverse Acculturation Conditions and Wellbeing of Mine Employees in the North-West Province. Journal of Psychology in Africa, 21(3):385-396

Judd, C. M., \& Kenny, D. A. (1981). Process analysis: Estimating mediation in treatment evaluations. Evaluation Review, 5:602-619.

Kessler, R.C., Mickelson, K.D., \& Williams, D.R., (1999). The prevalence, distribution, and mental health correlates of perceived discrimination in the United States. Journal of Health and Social Behavior, 40:208-230.

Kline, R. B. (1998). Principles and practice of structural equation modelling. New York, NY: Guilford.

MacKinnon, D. P., Lockwood, C. M., Hoffman, J. M., West, S. G., \& Sheets, V. (2002). A comparison of methods to test mediation and other intervening variable effects. Psychological Methods, 7, 83-104.

Marisol, N. Antonio, J. R., Garcia, M., Pumares, P.. (2007). Acculturation strategies and attitudes according to the Relative Acculturation Extended Model (RAEM), The perspectives of natives versus immigrants. International Journal of Intercultural Relations; Science Direct, 30(5).

Mallinckrodt, B., \& Leong , F. T. (1992). International graduate students, stress, and social support. Journal of College Student Development, 33:71-78.

Moomal H. Jackson, P.B., Stein, D.J., Herman, A., Myer, L., Seedat, S., MadelaMntla, E., Williams D.R., (2009) Perceived discrimination and mental health disorders, The South African Stress and Health study. May 2009, Vol. 99, No. 5 SAMJ.

Murphy, H. B. M. (1965). Migration and the major mental disorders. In M. B. Kantor (Ed.), Mobility and mental health ((p. 221-249)) London: Sagee 
Noh, S., Beiser, M., Kaspar, V., Hou, F., \& Rummens, J. (1999). Perceived racial discrimination, depression and coping. Journal of Health and Social Behaviour, 40(3):93 -207.

Nunnally, J. C, \& Bernstein, I. H. (1994). Psychometric theory (3rd edition). New York: McGraw-Hill.

Ong, A. D., Fuller-Rowell, T., \& Burrow, A. L. (2009). Racial discrimination and the stress process. Journal of Personality and Social Psychology, 96:1259-1271.

Pavalko, E.K., Mossakowski, K.N., \& Hamilton, V.J. (2003). Does Perceived discrimination Affect Health? Longitudinal Relationships between Work Discrimination and Women's Physical and Emotional Health. Journal of Health and Social Behavior 2003, 43 (March):18-33.

Pham, T.B., \& Harris, R.J. (2001). Acculturation strategies among VietnameseAmericans. International Journal of Intercultural Relations, 25(3):279-300.

Phinney, J.S. (1990). Ethnic identification in adolescence and adulthood: A review and integration. Psychological Bulletin, 108(3), 499-514.

Phinney, J.S. (1995). Ethnic identity and self-esteem: A review and integration. In A.M. Padilla (Ed.), Hispanic psychology: Critical issues in theory and research (pp. 57-70). Thousand Oaks, CA: Sage.

Parker, G., Chan, B., and Tully, L. (2006). "Recognition of Depressive Symptoms by Chinese Subjects: the Influence of Acculturation and Depressive Experience." Journal of Affective Disorders.

Preacher, K. J., \& Hayes, A. F. (2004). SPSS and SAS procedures for estimating indirect effects in simple mediation models. Behavior Research Methods, Instruments, \& Computers,36, 717-731.

Roscigno V.J. (2007). The Face of Discrimination: How Race and Gender Impact Work and Home Lives. Rowman \& Littlefield. Social Forces 7(4).

SPSS, Inc. (2003). SPSS 12.0 for Windows. Chicago, IL: SPSS

Spector, P. E., \& Jex, S. M. (1998). Development of four self-report measures of job stressors and strain: Interpersonal conflict and work scale, quantitative workload inventory. Journal of Occupational Health Psychology, 3(4):356-367.

Smith, T. B., Stones, C. R., \& Naidoo, A. (2003). Racial attitudes among South African young adults: A four year follow-up study. South African Journal of Psychology, 33(1):39-43.

Steyn, H. S., Jr. (1999). Praktiese beduidendheid: die gebruik van effekgroottes [Practical significance: The use of effect sizes]. Wetenskaplike bydraes, Reeks B: Natuurwetenskappe nr. 117, Potchefstroomse Universiteit vir $\mathrm{CHO}$, Potchefstroom. 
Swim, J. K., Aikin, K. J., Hall, W. S., \& Hunter, B. A. (1995). Sexism and racism: Old fashioned and modern prejudices. Journal of Personality and Social Psychology, 68(2):199-214.

Vedder, P., Van de Vijver, F. J. R., \& Liebkind, K. (2006). Predicting immigrant youths adaptation across countries and ethnocultural groups. In J. W. Berry, J. S. Phinney, D. L. Sam, \& P. Vedder (Eds.), Immigrant youth in cultural transition: Acculturation, identity and adaptation across national contexts (pp. 143-166). Mahwah, NJ: Erlbaum.

Van Wyk, E., (2011). Alleged racial attack just not cricket. Retrieved November 30, 2011, from http://www.news24.com/.

Vernellia, R. (2008). Defining Race Racism and Racial Discrimination. Retrieved November 02, 2011, from http://academic.udayton.edu/race/01race/race08.htm

Ward, C, \& Kennedy, (1992). Locus of control, mood disturbance, and social difficulty during cross-cultural transitions. International Journal of Intercultural Relations, 16(2):175-194.

Ward, C, \& Kennedy, A (1999). The measurement of sociocultural adaptation. International Journal of Inter cultural Relations, 23(4):659-677.

Ward C., \& Rana-Deuba, A. (1999). Acculturation and adaptation revisited. Journal of Cross-Cultural Psychology, 30(4):372-392.

Ward, C. (2001). The A, B, Cs of acculturation. In D. R. Matsumoto (Ed.), The handbook of culture and psychology (pp. 411-445). San Francisco: Oxford University Press.

Ward, C, Bochner, S., \& Furnham, A. (2001). The psychology of culture shock. London: Routledge.

Welman, C., Kruger, F., \& Mitchell, B., (2005). Research Methodology (3 ${ }^{\text {rd }}$ ed). Oxford Southern Africa. University Press.

World Health Organization. (1988). World Health Organization cross-national survey of psychological and somatic symptoms, Geneva, Switzerland.

Zagefka, H., \& Brown, R. (2002). The relationship between acculturation strategies, relative fit and intergroup relations: Immigration-majority relations in Germany. European Journal of Social Psychology, 32(2):171-188. 
ANNEXURE

\section{Acculturation Questionnaire}

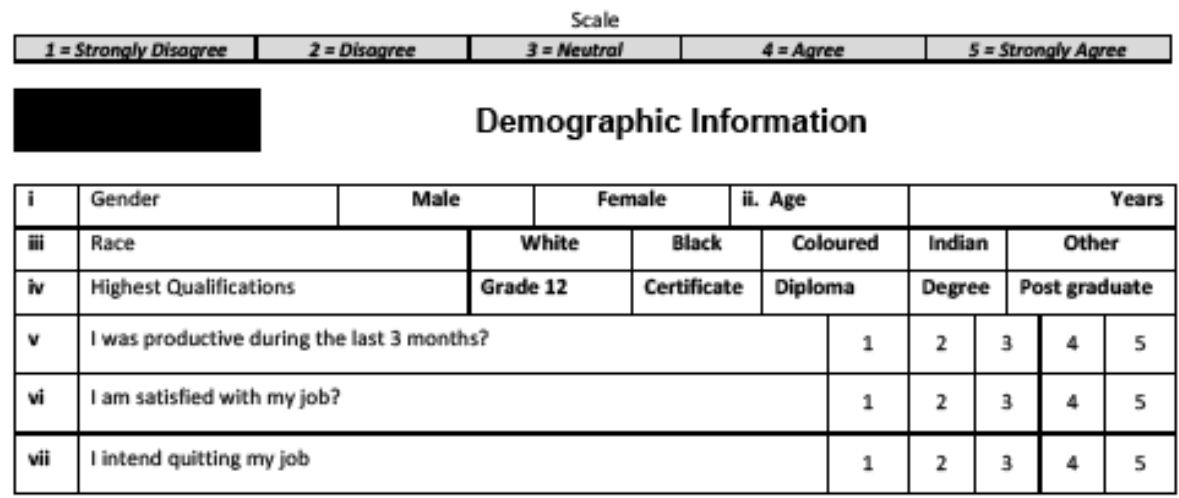

Please rate the extent to which you agree/disagree with the following statements by making an " $\mathrm{X}$ ' over the appropriate number on the 1 to 5 point scale next to the statement.

\begin{tabular}{|c|c|c|c|c|c|c|}
\hline & STATEMENT & \multicolumn{5}{|c|}{ SCALE } \\
\hline 1 & $\begin{array}{l}\text { I prefer social contact and interaction with ONLY members of my own ethnic } \\
\text { group }\end{array}$ & 1 & 2 & 3 & 4 & 5 \\
\hline 2 & $\begin{array}{l}\text { I want maintain my own culture and really do not seek contact and } \\
\text { participate in the mainstream culture }\end{array}$ & 1 & 2 & 3 & 4 & 5 \\
\hline 3 & $\begin{array}{l}\text { I want to adopt the new culture of the "Rainbow Nation" and do not want to } \\
\text { maintain my own culture }\end{array}$ & 1 & 2 & 3 & 4 & 5 \\
\hline 4 & $\begin{array}{l}\text { I would prefer that all ethnic groups in South Africa adopt the new culture of } \\
\text { the "Rainbow Nation" and forget about their own cultures }\end{array}$ & 1 & 2 & 3 & 4 & 5 \\
\hline 5 & I actually avoid contact with members from other cultures & 1 & 2 & 3 & 4 & 5 \\
\hline 6 & $\begin{array}{l}\text { I think that things would be better for me if I forget about my own culture } \\
\text { and adopt the dominant culture of the "New South Africa" }\end{array}$ & 1 & 2 & 3 & 4 & 5 \\
\hline 7 & $\begin{array}{l}\text { I do not want contact with members of my own ethnic group nor with } \\
\text { members from other cultures }\end{array}$ & 1 & 2 & 3 & 4 & 5 \\
\hline 8 & $\begin{array}{l}\text { I do not wish to maintain my own culture nor do I want to adopt to the } \\
\text { mainstream culture }\end{array}$ & 1 & 2 & 3 & 4 & 5 \\
\hline 9 & $\begin{array}{l}\text { I avoid contact with members of my group as well as members from other } \\
\text { cultural groups }\end{array}$ & 1 & 2 & 3 & 4 & 5 \\
\hline 10 & $\begin{array}{l}\text { I think that most of my co-workers would be happy to have people from } \\
\text { other cultures than their own thrown out of our organisation. }\end{array}$ & 1 & 2 & 3 & 4 & 5 \\
\hline 11 & $\begin{array}{l}\text { I think that most of my co-workers would be happy if all employees of our } \\
\text { organisation would come from their culture. }\end{array}$ & 1 & 2 & 3 & 4 & 5 \\
\hline 12 & $\begin{array}{l}\text { I think that most of my co-workers avoid contact with people from other } \\
\text { cultures. }\end{array}$ & 1 & 2 & 3 & 4 & 5 \\
\hline 13 & I think that most of my co-workers do not like to see people from my culture & 1 & 2 & 3 & 4 & 5 \\
\hline
\end{tabular}


Scale

\begin{tabular}{|c|c|c|c|c|c|c|}
\hline & \multirow[t]{2}{*}{ trangly Disarvee } & & \multicolumn{4}{|c|}{$5=$ Stronghy Aares } \\
\hline & & & & & & \\
\hline 14 & $\begin{array}{l}\text { I think that most of my co-workers believe that separate facilities (toilets, } \\
\text { tea rooms) should be created for different cultural groups. }\end{array}$ & 1 & 2 & 3 & 4 & 5 \\
\hline 15 & $\begin{array}{l}\text { I think that most of my co-workers believe that each cultural group should } \\
\text { have its own room for lunch and tea. }\end{array}$ & 1 & 2 & 3 & 4 & 5 \\
\hline 16 & $\begin{array}{l}\text { I think that most of my co-workers want to deal only with people from theit } \\
\text { own culture. }\end{array}$ & 1 & 2 & 3 & 4 & 5 \\
\hline 17 & $\begin{array}{l}\text { I think that most of co-workers would want to attend workshops only with } \\
\text { people from their own culture. }\end{array}$ & 1 & 2 & 3 & 4 & 5 \\
\hline 18 & $\begin{array}{l}\text { I think that most of my co-workers believe that each cultural group should } \\
\text { have its own social functions (braai, etc.). }\end{array}$ & 1 & 2 & 3 & 4 & 5 \\
\hline 19 & $\begin{array}{l}\text { I think that most of my co-workers believe that social contact between } \\
\text { different cultural groups should be limited as much as possible. }\end{array}$ & 1 & 2 & 3 & 4 & 5 \\
\hline 20 & $\begin{array}{l}\text { I think that most of my co-workers befieve that all employees should come } \\
\text { from the same cultural group. }\end{array}$ & 1 & 2 & 3 & 4 & 5 \\
\hline 21 & $\begin{array}{l}\text { I think that most of my co-workers do not want to want to be seen while } \\
\text { talking to someone from another cultural group. }\end{array}$ & 1 & 2 & 3 & 4 & 5 \\
\hline 22 & lexperience diserimination in our workplace. & 1 & 2 & 3 & 4 & 5 \\
\hline 23 & $\begin{array}{l}\text { My co-workers from other cultural groups want me to know what offends } \\
\text { members from their cuitural group but they don't want to know what } \\
\text { offends me. }\end{array}$ & 1 & 2 & 3 & 4 & 5 \\
\hline 24 & $\begin{array}{l}\text { When my home culture is mentioned at work, it is aimost always negatively } \\
\text { mentioned. }\end{array}$ & 1 & 2 & 3 & 4 & 5 \\
\hline 25 & My co-workers do not always treat everyone equal in our organisation. & 1 & 2 & 3 & 4 & 5 \\
\hline 26 & My culture is almost always negatively mentioned in jokes made at work. & 1 & 2 & 3 & 4 & 5 \\
\hline 27 & $\begin{array}{l}\text { My co-workers do not like my cultural habits and customs (language, food, } \\
\text { music, jokes). }\end{array}$ & 1 & 2 & 3 & 4 & 5 \\
\hline 28 & $\begin{array}{l}\text { My co-workers expect from me to learn everything about their culture } \\
\text { (language, food, jokes, music). }\end{array}$ & 1 & 2 & 3 & 4 & 5 \\
\hline 29 & $\begin{array}{l}\text { My co-workers do not make an effort to learn more about my culture } \\
\text { (language, food, jokes, music). }\end{array}$ & 1 & 2 & 3 & 4 & 5 \\
\hline 30 & Many co-workers brag about their own culture. & 1 & 2 & 3 & 4 & 5 \\
\hline 31 & $\begin{array}{l}\text { My cultural group is treated worse than other cultural groups in our } \\
\text { organisation. }\end{array}$ & 1 & 2 & 3 & 4 & 5 \\
\hline 32 & Affirmative action is reverse discrimination. & 1 & 2 & 3 & 4 & 5 \\
\hline 33 & Only people of other cultural groups are promoted in our organisation. & 1 & 2 & 3 & 4 & 5 \\
\hline
\end{tabular}


scale

\begin{tabular}{|c|c|c|c|c|c|c|}
\hline$I=$ Strangly Disaruee & \multicolumn{2}{|l|}{$3=$ Neutral } & \multicolumn{4}{|c|}{$5=$ Strongty Aaree } \\
\hline 34 & Jokes made by my co-workers from other cultures upset me. & 1 & 2 & 3 & 4 & 5 \\
\hline 35 & Race is the bases used when deciding to promote or not in our organisation. & 1 & 2 & 3 & 4 & 5 \\
\hline 36 & $\begin{array}{l}\text { Racial graffiti on the walls and doors of restrooms is accepted in our } \\
\text { organisation. }\end{array}$ & 1 & 2 & 3 & 4 & 5 \\
\hline 37 & $\begin{array}{l}\text { When reference is made to my cultural group in our organisations, it is } \\
\text { normally made in a negative sense. }\end{array}$ & 1 & 2 & 3 & 4 & 5 \\
\hline 38 & $\begin{array}{l}\text { Groups consisting of members from the same race are common in our } \\
\text { organisation. }\end{array}$ & 1 & 2 & 3 & 4 & 5 \\
\hline 39 & Excess to information is based on race in our organisation. & 1 & 2 & 3 & 4 & 5 \\
\hline 40 & Resources are distributed on the bases of race in our organisation. & 1 & 2 & 3 & 4 & 5 \\
\hline 41 & $\begin{array}{l}\text { Top management positions are only for other cultural groups in out } \\
\text { organisation. }\end{array}$ & 1 & 2 & 3 & 4 & 5 \\
\hline 42 & $\begin{array}{l}\text { Training opportunities are only provided for other cultural groups in our } \\
\text { organisation. }\end{array}$ & 1 & 2 & 3 & 4 & 5 \\
\hline 43 & $\begin{array}{l}\text { Most members of my cultural group want us to use separate facilities (es. } \\
\text { toilets, tea rooms) in our organisation. }\end{array}$ & 1 & 2 & 3 & 4 & 5 \\
\hline 44 & $\begin{array}{l}\text { Most members of my cultural group want us to avoid contact with members } \\
\text { from other cultural groups in our organisation. }\end{array}$ & 1 & 2 & 3 & 4 & 5 \\
\hline 45 & My cultural group want to protect its members from other cultural groups. & 1 & 2 & 3 & 4 & 5 \\
\hline 46 & $\begin{array}{l}\text { Mv cultural group believes that our way of doing is the most beneficial for } \\
\text { the organisation. }\end{array}$ & 1 & 2 & 3 & 4 & 5 \\
\hline 47 & $\begin{array}{l}\text { My cultural group members discourage each other to work together in a } \\
\text { multi-cultural group. }\end{array}$ & 1 & 2 & 3 & 4 & 5 \\
\hline 48 & $\begin{array}{l}\text { My cultural group members believe that we should only work with people } \\
\text { from our own culture in our organisation. }\end{array}$ & 1 & 2 & 3 & 4 & 5 \\
\hline 49 & $\begin{array}{l}\text { My cultural group members are willing to participate in activities with other } \\
\text { cultures in the workplace. }\end{array}$ & 1 & 2 & 3 & 4 & 5 \\
\hline 50 & In most ways my life is close to my ideal. & 1 & 2 & 3 & 4 & 5 \\
\hline 51 & The conditions of my life are excellent. & 1 & 2 & 3 & 4 & 5 \\
\hline 52 & I am satisfied with my life. & 1 & 2 & 3 & 4 & 5 \\
\hline 53 & So far I have got the important things I want in life. & 1 & 2 & 3 & 4 & 5 \\
\hline 54 & If I could live my life over I would change nothing. & 1 & 2 & 3 & 4 & 5 \\
\hline 55 & Life is worth living. & 1 & 2 & 3 & 4 & 5 \\
\hline
\end{tabular}

\section{3}


Scale

\begin{tabular}{|c|c|c|c|c|c|c|}
\hline$I=$ Strangly Disaruee & trangly Disarvee & $4=$ Aquese & \multicolumn{4}{|c|}{$5=$ Strongty Aaree } \\
\hline 56 & All in all, I am satisfied with my life these days. & 1 & 2 & 3 & 4 & 5 \\
\hline 57 & I often consider quitting my job & 1 & 2 & 3 & 4 & 5 \\
\hline 58 & I am looking for another job & 1 & 2 & 3 & 4 & s \\
\hline 59 & I frequently ask around for a job somewhere else & 1 & 2 & 3 & 4 & 5 \\
\hline
\end{tabular}

Over the last 3 months, how frequent have you experienced any of the following symptoms

\begin{tabular}{|l|l|l|l|l|}
\hline $1=$ Never & $2=$ Once a Month & $3=$ Once a week & $4=$ Few utmes a week & $5=$ Everyday \\
\hline
\end{tabular}

\begin{tabular}{|c|c|c|c|c|c|c|}
\hline 6 & Muscular tenslon / pain / aches: & 1 & 2 & 3 & 4 & 5 \\
\hline 61 & Low back pain / aches. & 1 & 2 & 3 & 4 & 5 \\
\hline 62 & Feeling sick. & 1 & 2 & 3 & 4 & 5 \\
\hline 63 & An upset stomach or nausea. & 1 & 2 & 3 & 4 & 5 \\
\hline 64 & A backoche. & 1 & 2 & 3 & 4 & 5 \\
\hline 65 & Trouble sleeping. & 1 & 2 & 3 & 4 & 5 \\
\hline 65 & A slinin rash. & 1 & 2 & 3 & 4 & 5 \\
\hline 67 & Shortness of breath. & 1 & 2 & 3 & 4 & 5 \\
\hline 68 & Chest pain. & 1 & 2 & 3 & 4 & 5 \\
\hline 69 & Headoche. & 1 & 2 & 3 & 4 & 5 \\
\hline 70 & Fever. & 1 & 2 & 3 & 4 & 5 \\
\hline$n$ & Acid indigestion or heartburn. & 1 & 2 & 3 & 4 & 5 \\
\hline $\boldsymbol{n}$ & Eye strain. & 1 & 2 & 3 & 4 & 5 \\
\hline 73 & Diarmoea. & 1 & 2 & 3 & 4 & 5 \\
\hline 74 & Stomsch cramps (Not menstrual). & 1 & 2 & 3 & 4 & 5 \\
\hline 75 & Constipation. & 1 & 2 & 3 & 4 & 5 \\
\hline 76 & Heart pounding when not exerclsing. & 1 & 2 & 3 & 4 & 5 \\
\hline$n$ & An infection. & 1 & 2 & 3 & 4 & 5 \\
\hline 78 & Loss of appetite. & 1 & 2 & 3 & 4 & 5 \\
\hline 79 & Dizziness. & 1 & 2 & 3 & 4 & 5 \\
\hline 80 & Tiredness or fatigue. & 1 & 2 & 3 & 4 & 5 \\
\hline 81 & Panic/Anxiety attacks. & 1 & 2 & 3 & 4 & 5 \\
\hline 82 & Constant irritability. & 1 & 2 & 3 & 4 & 5 \\
\hline 83 & Difficulty in making declsions. & 1 & 2 & 3 & 4 & 5 \\
\hline 84 & Feeling / becoming easily angry. & 1 & 2 & 3 & 4 & 5 \\
\hline 85 & Feeling unable to solve daily probiems. & 1 & 2 & 3 & 4 & 5 \\
\hline
\end{tabular}


Scale

\begin{tabular}{|l|l|l|l|l|l|l|l|}
\hline $1=$ Strongly Disaqree & \multicolumn{1}{|c|}{$2=$ Disagree } & \multicolumn{3}{|c|}{$4=$ Neutral } & \multicolumn{3}{|c|}{$5=$ Strongly Aqree } \\
\hline 86 & Avoiding contact with other people. & 1 & 2 & 3 & 4 & 5 \\
\hline 87 & Mood swings. & 1 & 2 & 3 & 4 & 5 \\
\hline 88 & Unable to listen to other people. & 1 & 2 & 3 & 4 & 5 \\
\hline 89 & Having difficulty concentrating. & 1 & 2 & 3 & 4 & 5 \\
\hline
\end{tabular}

\section{5}

